NIPER-696

Distribution Category UC-122

\title{
DERIVING THE SHAPE FACTOR OF A FRACTURED ROCK MATRIX
}

Topical Report

By

Ming-Ming Chang

September 1993

Work Performed Under Cooperative Agreement No. DE-FC22-83FE60149

Prepared for

U.S. Department of Energy Assistant Secretary for Fossil Energy

Thomas B. Reid, Project Manager

Bartlesville Project Office

P. O. Box 1398

Bartlesville, OK 74005

Prepared by

IIT Research Institute

National Institute for Petroleum and Energy Research

P.O. Box 2128

Bartlesville, OK 74005 


\section{DISCLAIMER}

This report was prepared as an account of work sponsored by an agency of the United States Government. Neither the United States Government nor any agency thereof, nor any of their employees, make any warranty, express or implied, or assumes any legal liability or responsibility for the accuracy, completeness, or usefulness of any information, apparatus, product, or process disclosed, or represents that its use would not infringe privately owned rights. Reference herein to any specific commercial product, process, or service by trade name, trademark, manufacturer, or otherwise does not necessarily constitute or imply its endorsement, recommendation, or favoring by the United States Government or any agency thereof. The views and opinions of authors expressed herein do not necessarily state or reflect those of the United States Government or any agency thereof. 


\section{DISCLAIMER}

Portions of this document may be illegible in electronic image products. Images are produced from the best available original document. 


\section{TABLE OF CONTENTS}

PAGE

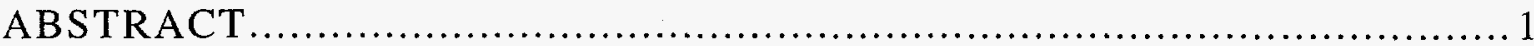

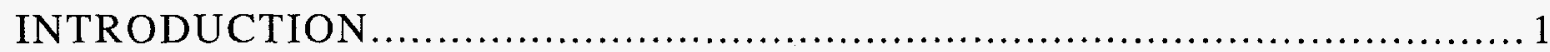

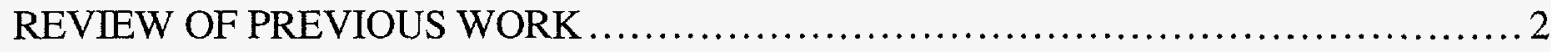

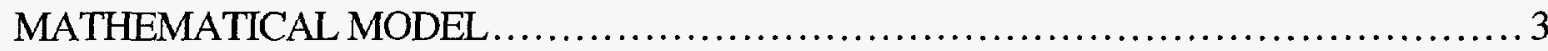

SOLUTIONS FOR CONSTANT FRACTURE PRESSURE $\ldots \ldots \ldots \ldots \ldots \ldots \ldots \ldots \ldots \ldots . \ldots$

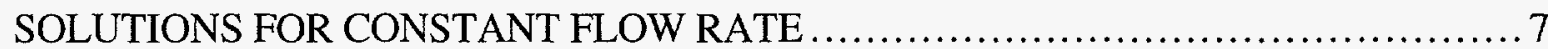

SOLUTIONS FOR CONSTANT FRACTURE PRESSURE FOLLOWED BY

LINEARLY DECLINING FRACTURE PRESSURE .8

SOLUTIONS FOR LINEARLY DECLINING FRACTURE PRESSURE FOLLOWED BY CONSTANT FRACTURE PRESSURE

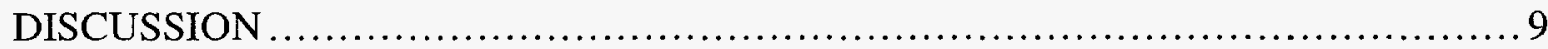

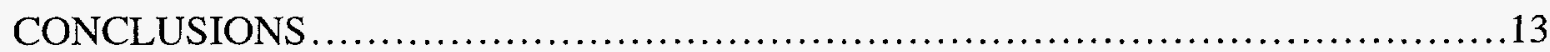

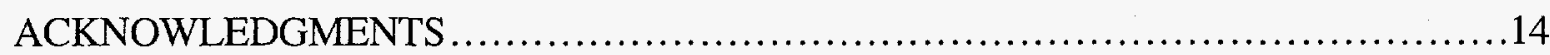

NOMENCLATURE.............................................................

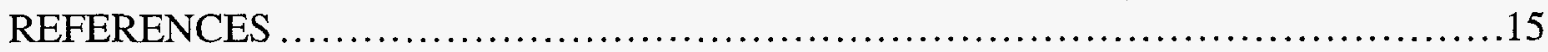

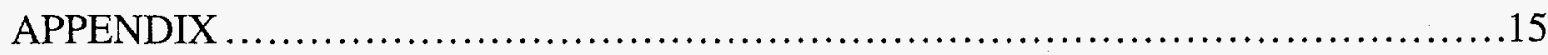




\section{TABLE OF CONTENTS --- Continued}

PAGE

TABLE

1. Comparison of shape factors.................................................

\section{ILLUSTRATIONS}

FIGURE

1. 3-D dimensionless pressure drawdown for constant fracture pressure $\left(t_{D}=0.032\right) \ldots 17$

2. 3-D dimensionless pressure drawdown for constant fracture pressure $\left(t_{D}=0.158\right) \ldots 18$

3. 2-D dimensionless pressure drawdown for constant fracture pressure .............. 19

4. 1-D dimensionless pressure drawdown for constant fracture pressure $\ldots \ldots \ldots \ldots \ldots \ldots 20$

5. Average dimensionless pressure drawdown of central layer for constant fracture

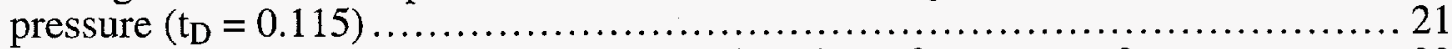

6. History of average dimensionless pressure drawdown for constant fracture pressure 22

7. Shape factors with depletion time for constant fracture pressure $\ldots \ldots \ldots \ldots \ldots \ldots \ldots \ldots 23$

8. History of flow rate and Average dimensionless pressure drawdown for constant

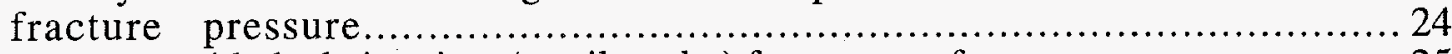

9. Flow rate with depletion time (semilog plot) for constant fracture pressure ......... 25

10. Flow rate with depletion time (log-log plot) for constant fracture pressure $\ldots \ldots \ldots \ldots .26$

11. 3-D dimensionless pressure drawdown for constant flow rate $\left(t_{D}=0.032\right) \ldots \ldots \ldots .27$

12. 3-D dimensionless pressure drawdown for constant flow rate $\left(t_{D}=0.158\right) \ldots \ldots \ldots .28$

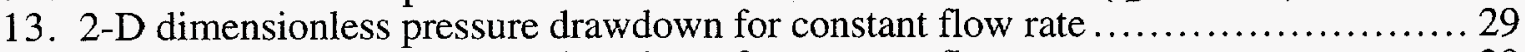

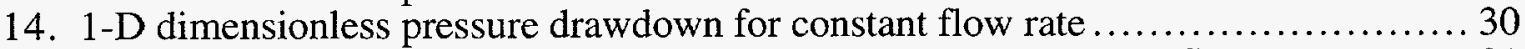

15. 1-D dimensionless pressure drawdown (semilog plot) for constant flow rate........ 31

16. History of average dimensionless pressure drawdown (log-log plot) for constant flow

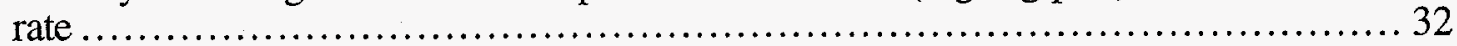

17. History of average dimensionless pressure drawdown for constant flow rate.......... 33

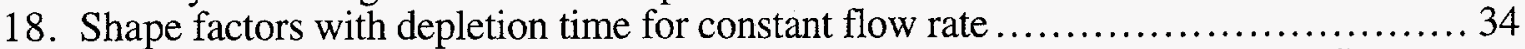

19. Comparison of shape factors for constant fracture pressure and for constant flow rate

20. 1 -D dimensionless pressure drawdown for constant fracture pressure followed by

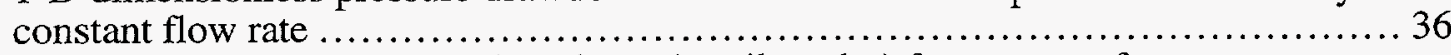

21. 1-D dimensionless pressure drawdown (semilog plot) for constant fracture pressure followed by linearly declining fracture pressure ................................... 37

22. 1-D flow rate and dimensionless pressure drawdown for constant fracture pressure followed by linearly declining fracture pressure ................................ 38

23. 1-D shape factor for constant fracture pressure followed by linearly declining fracture

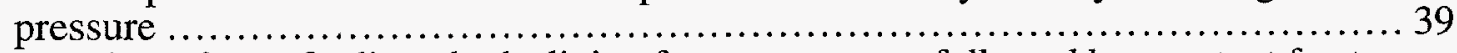

24. 1-D shape factor for linearly declining fracture pressure followed by constant fracture

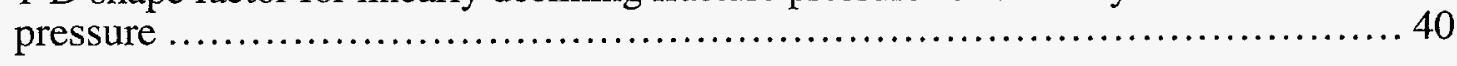




\title{
DERIVING THE SHAPE FACTOR OF A FRACTURED ROCK MATRIX
}

\author{
By Ming-Ming Chang
}

\begin{abstract}
Fluid flow from a fractured rock matrix was investigated for accurately predicting oil recovery from fractured reservoirs. To relate the oil rate with rock geometry and average rock matrix pressure, a shape factor is used in the mathematical model of fractured reservoirs. The shape factor in the transfer function was derived by solving the three-dimensional diffusivity equation of a rock matrix block under unsteady-state production, in contrast to the quasi-steadystate condition assumed by most previous studies denoted in the literature. The diffusivity equation in the $\mathrm{x}, \mathrm{y}$, and $\mathrm{z}$ coordinate was solved in four cases by assuming different boundary conditions of (1) constant fracture pressure; (2) constant flow rate; (3) constant fracture pressure followed by linearly declining fracture pressure; and (4) linearly declining fracture pressure followed by constant fracture pressure.
\end{abstract}

Shape factor values are high at the initial depletion stage under an unsteady-state condition. When the fracture pressure is constant, the shape factor converges to $\pi^{2} / \mathrm{L}^{2}, 2 \pi^{2} / \mathrm{L}^{2}$, and $3 \pi^{2} / \mathrm{L}^{2}$ for one-, two-, and three-dimensional rock matrix, respectively, at the dimensionless time ( $\tau$ ) of about 0.1 . The ' $L$ ' value in the shape factor equation is the length of rock matrix. The period of 0.1 for $\tau$ ranges from less than 1 day for commonly encountered fractured reservoirs to months for large and tight fractured rock.

When the flow rate between the rock matrix and the fracture is constant, the fracture pressure varies with location on the rock surface. Based on the average fracture pressure, the shape factor decreases with production time until a $\tau$ value of 0.1 is reached. The shape factor values converging at 0.1 are $12 / \mathrm{L}^{2}, 24 / \mathrm{L}^{2}$, and $36 / \mathrm{L}^{2}$, for one-, two-, and three-dimensional rock matrix flow, respectively. After reaching quasi-steady-state, the shape factors calculated from the case of constant flow rate are 1.2 times those from the case of constant fracture pressure.

The boundary conditions of constant fracture pressure followed by a constant decline in fracture pressure are equivalent to the condition of a constant fracture pressure followed by a period of constant flow rate. The shape factor values in this case for one-dimensional flow are between $\pi^{2} / \mathrm{L}^{2}$ and $12 / \mathrm{L}^{2}$ at quasi-steady-state.

The shape factor values calculated from unsteady-state production are higher than those proposed by Kazemi and by Coats, but less than or equal to those by Warren and Roots.

\section{INTRODUCTION}

Natural fractures are common in hydrocarbon reservoirs. The fluid flow mechanism in fractured rocks is critical for producing oil from such reservoirs. The presence of interconnected open fractures significantly improves the oil production from low-permeability reservoirs using vertical or horizontal wells. Formation fracture are so important that $70 \%$ of the horizontal drilling permits issued from May 1991 through April 1992 were targeted to fractured Austin Chalk reservoirs. Formation fracture is also the major production mechanism for horizontal wells in the second-ranking Lower Cretaceous Buda Limestone in Texas and the third-ranking Bakken Shale in North Dakota. At present we do not understand the effects of reservoir fractures on horizontal well production well enough to provide a reliable performance prediction. The objective of this study is 
to investigate fluid flow from fractured rock matrix by solving the diffusivity equation under unsteady-state production conditions. This analytical solution is then taken to derive the shape factor to be used in a dual-porosity or dual-permeability numerical reservoir simulator.

Many fractured reservoirs are characterized by an interconnected fracture network dividing the matrix rock into a multitude of separate blocks. Interconnected open fractures normally contribute little pore volume to a reservoir, but act as highly conductive flow channels throughout the reservoir. The rock matrix blocks, which contribute the main portion of the reservoir pore volume, have much smaller permeabilities than do the fractures. Flow between the matrix block and the fracture is essential to the productivity of fractured formations. This rock matrix flow can be accounted for by a shape factor in a transfer function. This transfer function is a form of Darcy's law expressed in terms of some mean path between the matrix block and the adjacent fracture*:

$$
q=\frac{k V}{\mu} \sigma\left(p_{f}-\overline{p_{m}}\right)
$$

where $\sigma$, the shape factor, can be rewritten as

$$
\sigma=\frac{\mathrm{q} \mu}{\mathrm{kV}\left(\mathrm{p}_{\mathrm{f}}-\overline{\mathrm{p}_{\mathrm{m}}}\right)}
$$

Equation 1 depends on a discrete gradient given by the distance, $\Delta \mathrm{L}$, between the pressure at the fracture and the block's average internal pressure. Comparing Eq. 1 to the transfer flow in the Darcy flow format:

$$
q=\frac{k A}{\mu} \frac{\left(p_{f}-\overline{p_{m}}\right)}{\Delta L}
$$

we obtain $\sigma=\mathrm{A} /(\mathrm{V} \Delta \mathrm{L})$

or

$$
\Delta \mathrm{L}=\mathrm{A} /(\mathrm{V} \sigma)
$$

For the linear flow to or from two opposite rock surfaces, the right-hand sides of Eqs. 3, 4, and 5 need to be multiplied by 2 , respectively. An accurate value of shape factor is needed to properly account for the fluid flow between the fracture and the rock matrix in model calculations.

The derivation of accurate shape factors in this study can be used to improve the accuracy of dual-porosity reservoir simulators. This report completes task 2 of DOE Supplemental Government Project 73 in FY93 for improving the transfer function in the dual-porosity simulators.

\section{REVIEW OF PREVIOUS WORK}

Numerous equations were derived for calculating the shape factor of fractured rock. All equations developed were based on the assumption of single-phase flow in the rock matrix.

Warren and Root $^{1}$ proposed a equation for the shape factor as

$$
\sigma=4 \mathrm{~N}(\mathrm{~N}+2) / \mathrm{L}^{2}
$$

* definition of terms is in the nomenclature section. 
where $\mathrm{L}$ is the length of the matrix block and $\mathrm{N}$ is the number of normal sets of fractures: 1,2 , or 3. If rock blocks have dimensions $\mathrm{a}, \mathrm{b}$, and $\mathrm{c}$, then

$$
\begin{aligned}
& L=a \text { for } N=1 \\
& L=2 a b /(a+b) \text { for } N=2 \\
& L=3 a b c /(a b+b c+c a) \text { for } N=3
\end{aligned}
$$

The basis of this equation is not known.

The shape factor equation proposed by $\mathrm{Kazemi}^{2}$ for a cubic matrix block is $4 \mathrm{~N} / \mathrm{L}^{2}$. Kazemi's equation can be derived based on quasi-steady-state (QSS) flow and the assumption that $\overline{\mathrm{p}_{\mathrm{m}}}$ equals the pressure in the center of the matrix block, or $\Delta \mathrm{L}$ is equal to $\mathrm{L} / 2$. Kazemi's equation has been adopted for several dual-porosity or dual-permeability simulators.

Peaceman ${ }^{3}$ evaluated gas and oil transfer between the fracture and the rock matrix. The corresponding shape factor of Peaceman's transfer coefficient is $12 / \mathrm{L}^{2}, 14.23 / \mathrm{L}^{2}$, and $16.53 / \mathrm{L}^{2}$ for the one-, two-, and three-dimensional cubic rock matrix, respectively. The value of Peaceman's transfer coefficient or shape factor does not increase much with an increase in the number of normal sets of fractures.

By matching the fracture modeling results with oil recovery through water imbibition from single-cell experiments, Thomas et al. ${ }^{4}$ found shape factors of 25 and 0.25 for 1 - and 10 -ft cubic blocks, respectively. This is equivalent to a equation of $25 / \mathrm{L}^{2}$ for the shape factor. Using area and length values corresponding to the centroid of one of the six equilateral pyramids in a cube of side $\mathrm{L}$, Thomas et al. derived a shape factor of $36.6 / \mathrm{L}^{2}$.

By doubling Kazemi's shape factor value, Ueda et al. ${ }^{5}$ closely matched their modeling results with their laboratory experimental results or fine-grid simulation results. Ueda et al. believed that Kazemi's shape factor value needed to be adjusted by a factor of 2 and 3 for one- and two-dimensional rock matrix flow, respectively.

For single-phase flow at QSS, Coats $^{6}$ solved the diffusivity equation to give a shape factor of $12 / \mathrm{L}^{2}, 28.45 / \mathrm{L}^{2}$, and $49.58 / \mathrm{L}^{2}$ for the one-, two-, and three-dimensional cubic rock matrix, respectively. However, Coats recommended to use $8 \mathrm{~N} / \mathrm{L}^{2}$ for calculating the shape factor.

By matching the outflow function of rock matrix, derived from an unsteady diffusivity equation, at its $50 \%$ value, de Swaan ${ }^{7}$ found approximation to shape factor at QSS for cube and strata as $60 / \mathrm{L}^{2}$ and $15 / \mathrm{L}^{2}$, respectively. Functions for parallelepipeds within the two extreme shapes can be fitted by using factors intermediate between the two extreme shape factor values. In contrast to de Swaan's work, the change of shape factor values with production time was investigated in this study by solving the unsteady diffusivity equation.

\section{MATHEMATICAL MODEL}

Since many fractured reservoirs are characterized by a multitude of separate blocks divided by an interconnected fractured network, the model investigated in this study was a parallelepiped rock matrix with lengths of $a, b$, and $c$, in three normal directions, respectively. The unsteady flow of a slightly compressible single-phase fluid of constant viscosity was considered in an anisotropic rock matrix. The pressure distribution was analyzed for one-, two-, and three-dimensional flow 
between the rock matrix and the fracture in the $\mathrm{x}, \mathrm{y}$, and $\mathrm{z}$ Cartesian coordinate. The diffusivity equation solved for the flow was:

$$
\mathrm{k}_{\mathrm{x}} \frac{\partial^{2} \mathrm{p}}{\partial \mathrm{x}^{2}}+\mathrm{k}_{\mathrm{y}} \frac{\partial^{2} \mathrm{p}}{\partial \mathrm{y}^{2}}+\mathrm{k}_{\mathrm{z}} \frac{\partial^{2} \mathrm{p}}{\partial \mathrm{z}^{2}}=\phi \mu \mathrm{c}_{\mathrm{t}} \frac{\partial \mathrm{p}}{\partial \mathrm{t}}
$$

The initial pressure was assumed uniform throughout the rock matrix, or

$$
\mathrm{p}=\mathrm{p}_{\mathrm{i}} \text { when } \mathrm{t}=0
$$

The pressure and fluid flow of the rock matrix was solved for four cases by assuming different boundary conditions of (1) constant fracture pressure; (2) constant flow rate; (3) constant fracture pressure followed by linearly declining fracture pressure; and (4) linearly declining fracture pressure followed by constant fracture pressure. For constant fracture pressure,

$$
\mathrm{p}=\mathrm{p}_{\mathrm{f}} \text { at } \mathrm{x}=0 \text { or } \mathrm{a} ; \text { or } \mathrm{y}=0 \text { or } \mathrm{b} \text {; or } \mathrm{z}=0 \text { or } \mathrm{c}
$$

For constant flow rate in the y direction,

$$
\frac{\partial \mathrm{p}}{\partial \mathrm{y}}=\mathrm{C} \text { at } \mathrm{y}=0 \text { or } \mathrm{b}
$$

where $\mathrm{C}$ is a constant. Similar boundary conditions were extended to $\mathrm{x}$ and $\mathrm{z}$ directions for twoand three-dimensional flow.

For constant fracture pressure followed by linearly declining fracture pressure in a onedimensional (1-D) model, the boundary conditions at $\mathrm{y}=0$ and $\mathrm{y}=\mathrm{b}$ were

$$
\begin{aligned}
& \mathrm{p}_{\mathrm{f}}=\mathrm{p}_{\mathrm{i}}-\Delta \mathrm{p}_{0} \text { when } \mathrm{t} \leq \mathrm{t}_{0} \\
& \mathrm{p}_{\mathrm{f}}=\mathrm{p}_{\mathrm{i}}-\Delta \mathrm{p}_{0}-\kappa\left(\mathrm{t}-\mathrm{t}_{0}\right) \text { when } \mathrm{t}>\mathrm{t}_{0}
\end{aligned}
$$

where $\Delta \mathrm{p}_{0}$ is defined as the difference between the initial matrix pressure $\left(\mathrm{p}_{\mathrm{i}}\right)$ and fracture pressure $\left(\mathrm{p}_{\mathrm{f}}\right)$ at $\mathrm{t}=0$. For linearly declining fracture pressure followed by constant fracture pressure in a 1-D model, the boundary conditions at $\mathrm{y}=0$ and $\mathrm{y}=\mathrm{b}$ were

$$
\begin{aligned}
& p_{f}=p_{i}-\kappa t \text { when } t \leq t_{0} \\
& p_{f}=p_{i}-\kappa t_{0} \text { when } t>t_{0}
\end{aligned}
$$

To express the analysis in the dimensionless form, definitions of the following terms were introduced.

$$
\begin{aligned}
& \text { dimensionless distance: } x_{D}=\frac{x}{a}, \quad y_{D}=\frac{y}{b}, \text { and } z_{D}=\frac{z}{c} \\
& \text { dimensionless pressure: } p_{D}=\frac{p_{i}-p}{p_{i}-p_{f}} \\
& \text { dimensionless time } \tau \text { or } t_{D}: \quad \tau=\frac{k_{x} t}{a^{2} \phi \mu c_{t}}
\end{aligned}
$$


Thus, Eqs. 8 through 15 were converted, respectively, into:

$$
\begin{aligned}
& \frac{\partial^{2} \mathrm{p}_{\mathrm{D}}}{\partial \mathrm{x}_{\mathrm{D}}^{2}}+\mathrm{K}_{\mathrm{y}} \frac{\partial^{2} \mathrm{p}_{\mathrm{D}}}{\partial \mathrm{y}_{\mathrm{D}}^{2}}+\mathrm{K}_{\mathrm{z}} \frac{\partial^{2} \mathrm{p}_{\mathrm{D}}}{\partial \mathrm{z}_{\mathrm{D}}^{2}}=\frac{\partial \mathrm{p}_{\mathrm{D}}}{\partial \tau} \\
& \text { where } \mathrm{K}_{\mathrm{y}}=\frac{\mathrm{a}^{2} \mathrm{k}_{\mathrm{y}}}{\mathrm{b}^{2} \mathrm{k}_{\mathrm{x}}}, \quad \text { and } \mathrm{K}_{\mathrm{z}}=\frac{\mathrm{a}^{2} \mathrm{k}_{\mathrm{z}}}{\mathrm{c}^{2} \mathrm{k}_{\mathrm{x}}}
\end{aligned}
$$

initial condition: $\quad\left[\mathrm{P}_{\mathrm{D}}\right]_{\tau=0}=0$

boundary conditions for constant fracture pressure case:

$$
\begin{aligned}
& {\left[\mathrm{pD}_{\mathrm{X}_{\mathrm{D}}=0,1}=1\right.} \\
& {\left[\mathrm{pD}_{\mathrm{D}}\right]_{\mathrm{y}_{\mathrm{D}}=0,1}=1} \\
& {\left[\mathrm{pD}_{\mathrm{D}}\right]_{\mathrm{Z}_{\mathrm{D}}=0,1}=1}
\end{aligned}
$$

boundary conditions for constant flow rate case:

$$
\begin{aligned}
& {\left[\frac{\partial \mathrm{p}_{\mathrm{Dy}}}{\partial \mathrm{y}_{\mathrm{D}}}\right]_{\mathrm{y}_{\mathrm{D}}=1}=\mathrm{u}_{\mathrm{y}}} \\
& {\left[\frac{\partial \mathrm{p}_{\mathrm{Dy}}}{\partial \mathrm{y}_{\mathrm{D}}}\right]_{\mathrm{y}_{\mathrm{D}}=0}=\mathrm{u}_{\mathrm{y}}}
\end{aligned}
$$

where $\mathrm{u}_{\mathrm{y}}=\mathrm{Cb} / \Delta \mathrm{p}_{0}$. Boundary conditions similar to those of $11 \mathrm{a}$ and $11 \mathrm{~b}$ were assigned in $\mathrm{x}$ and $\mathrm{z}$ directions for the rock matrix having 2 or 3 normal sets of fractures. Boundary conditions for constant fracture pressure followed by linearly declining fracture pressure were

$$
\begin{aligned}
& p_{f}=p_{i}-\Delta p_{0} \text { when } \tau \leq \tau_{0} \\
& p_{f}=p_{i}-\Delta p_{0}-\kappa^{\prime}\left(\tau-t_{0}\right) \text { when } \tau>\tau_{0}
\end{aligned}
$$

where $K^{\prime}=K t / \tau$. Boundary conditions for linearly declining fracture pressure followed by constant fracture pressure were:

$$
\begin{aligned}
& p_{f}=p_{i}-\kappa^{\prime} \tau \text { when } \tau \leq \tau_{0} \\
& p_{f}=p_{i}-K^{\prime} \tau_{0} \text { when } \tau>\tau_{0}
\end{aligned}
$$

\section{SOLUTIONS FOR CONSTANT FRACTURE PRESSURE}

Using the method of separation of variables, $\mathrm{p}_{\mathrm{D}}$ in Eq. 8a was solved for three-dimensional (3-D) fluid flow subject to conditions $9 \mathrm{a}$ and $10 \mathrm{a}$ as 
$\mathrm{p}_{\mathrm{D}}=1-64 \pi^{3} \sum_{\mathrm{l}=0}^{\infty} \sum_{\mathrm{m}=0}^{\infty} \sum_{\mathrm{n}=0}^{\infty} \frac{\exp (-\mathrm{Ft})}{(2 \mathrm{l}+1)(2 \mathrm{~m}+1)(2 \mathrm{n}+1)} \sin (2 \mathrm{l}+1) \pi \mathrm{x}_{\mathrm{D}} \cdot \sin (2 \mathrm{~m}+1) \pi \mathrm{y}_{\mathrm{D}} \bullet \sin (2 \mathrm{n}+1) \pi \mathrm{z}_{\mathrm{D}}$

where $\quad F=\left[(2 l+1)^{2} \frac{k_{x}}{a^{2}}+(2 m+1)^{2} \frac{k_{y}}{b^{2}}+(2 n+1)^{2} \frac{k_{z}}{c^{2}}\right] \frac{\pi^{2}}{\phi \mu c_{t}}$

The corresponding flow rate at $\mathrm{x}=\mathrm{a}$ was:

$$
\mathrm{q}_{\mathrm{x}=\mathrm{a}}=256\left(\mathrm{p}_{\mathrm{m}}-\mathrm{p}_{\mathrm{f}}\right) \frac{\mathrm{k}_{\mathrm{x}} \mathrm{bc}}{\mu \mathrm{a} \pi^{4}} \sum_{\mathrm{l}=0}^{\infty} \sum_{\mathrm{m}=0}^{\infty} \sum_{\mathrm{n}=0}^{\infty} \frac{1}{(2 \mathrm{~m}+1)^{2}(2 \mathrm{n}+1)^{2}} \exp (-\mathrm{Ft})
$$

The average pressure in the rock matrix were obtained by integrating $\mathrm{p}_{\mathrm{D}}$ in Eq. 19:

$$
\overline{\mathrm{p}}_{\mathrm{D}}=1-\frac{512}{\pi^{6}} \sum_{\mathrm{I}=0}^{\infty} \sum_{\mathrm{m}=0}^{\infty} \sum_{\mathrm{n}=0}^{\infty} \frac{1}{(21+1)^{2}(2 \mathrm{~m}+1)^{2}(2 \mathrm{n}+1)^{2}} \exp (-\mathrm{Ft})
$$

and the shape factor was calculated using Eq. 2 as

$$
\sigma=\frac{\gamma_{1}}{\gamma_{2}}
$$

where

$$
\begin{aligned}
& \gamma_{1}=\pi^{2} \sum_{1=0}^{\infty} \sum_{m=0}^{\infty} \sum_{n=0}^{\infty} \frac{\exp (-F t)}{(2 l+1)^{2}(2 m+1)^{2}(2 n+1)^{2}}\left[\frac{(2 l+1)^{2}}{a^{2}}+\frac{(2 m+1)^{2}}{b^{2}}+\frac{(2 n+1)^{2}}{c^{2}}\right] \\
& \gamma_{2}=\sum_{1=0}^{\infty} \sum_{m=0}^{\infty} \sum_{n=0}^{\infty} \frac{1}{(21+1)^{2}(2 m+1)^{2}(2 n+1)^{2}} \exp (-F t)
\end{aligned}
$$

Solutions of $\mathrm{pD}_{\mathrm{D}}, \mathrm{q}$, and $\sigma$ were also obtained from two-dimensional (2-D) and 1-D flow diffusivity equations, respectively. For the 1-D matrix-fracture flow in the $\mathrm{x}$-direction, the shape factor was

$$
\sigma_{1 D}=\frac{\pi^{2}}{a^{2}} \frac{\sum_{m=0}^{\infty} \exp \left[-(2 m+1)^{2} \pi \tau\right]}{\sum_{m=0}^{\infty} \frac{1}{(2 m+1)^{2}} \exp \left[-(2 m+1)^{2} \pi \tau\right]}
$$

The shape factors shown in Eqs. 23 through 26 were time-dependent under the unsteady flow condition. As flow time proceeded, the shape factor value for 1-D flow in Eq. 23 converged to $\pi^{2} / \mathrm{a}^{2}$ at QSS. This convergence was seen by the sharp decline of values of the second $(\mathrm{m}=1)$ and following $(m>1)$ terms in comparison to the first term $(m=0)$ for both numerator and denominator series as $\tau$ value increased. Thus, the numerator and denominator series in Eq. 26 were canceled out at large time values. For the same reason, the shape factor for 3-D flow in the fractured rock converged to $\pi^{2}\left(1 / \mathrm{a}^{2}+1 / \mathrm{b}^{2}+1 / \mathrm{c}^{2}\right)$ with time. 


\section{SOLUTIONS FOR CONSTANT FLOW RATE}

Under the constant flow rate condition, the diffusivity equation was solved for the pressure and flow in the one-direction case first. The solutions to the 2- and 3-D diffusivity Eq. 8 were then derived from the "1-D" solution based on the principle of superposition.

The diffusivity equation for the y-direction flow was given by

$$
\frac{\partial^{2} p_{D y}}{\partial x_{D}^{2}}+K_{y} \frac{\partial^{2} p_{D y}}{\partial y_{D}^{2}}+K_{z} \frac{\partial^{2} p_{D y}}{\partial z_{D}^{2}}=\frac{\partial p_{D y}}{\partial \tau}
$$

Equation 27 was solved in two steps. In the first step, boundary conditions of Eqs. 28a through $28 \mathrm{e}$ were assumed in addition to the initial condition $9 \mathrm{a}$ and boundary condition $11 \mathrm{a}$.

$$
\begin{aligned}
& {\left[\frac{\partial P_{D y}}{\partial x_{D}}\right]_{x_{D}=0}=0} \\
& {\left[\frac{\partial P_{D y}}{\partial x_{D}}\right]_{x_{D}=1}=0} \\
& {\left[\frac{\partial P_{D y}}{\partial z_{D}}\right]_{z_{D}=0}=0} \\
& {\left[\frac{\partial P_{D y}}{\partial z_{D}}\right]_{z_{D}=1}=0} \\
& {\left[\frac{\partial P_{D y}}{\partial y_{D}}\right]_{y_{D}=0}=0}
\end{aligned}
$$

Equations 28a through 28e assumed no flow to the fracture at $\mathrm{x}_{\mathrm{D}}=0, \mathrm{x}_{\mathrm{D}}=1, \mathrm{z}_{\mathrm{D}}=0, \mathrm{z}_{\mathrm{D}}=1$, and $y_{D}=0$, respectively. Flow was allowed only at $y_{D}=1$ at a constant pressure gradient $u_{y}$ (Eq. 11a). Using the Laplace transform method, the dimensionless pressure was solved from Eq. 27 as:

$$
\begin{aligned}
p_{D y} & =u_{y} \sum_{n=0}^{\infty}\left[2 \sqrt{\frac{\tau K_{y}}{\pi}}\left(\exp \left(\frac{-\left(2 n+1-y_{D}\right)^{2}}{4 K_{y} \tau}\right)+\exp \left(\frac{-\left(2 n+1+y_{D}\right)^{2}}{4 K_{y} \tau}\right)\right)\right. \\
& \left.-\left(2 n+1-y_{D}\right) \operatorname{erfc}\left(\frac{\left(2 n+1-y_{D}\right)}{2 \sqrt{K_{y} \tau}}\right)-\left(2 n+1+y_{D}\right) \operatorname{erfc} \frac{\left(2 n+1+y_{D}\right)}{2 \sqrt{K_{y} \tau}}\right]
\end{aligned}
$$

In the second step, Eq. 27 was solved based on conditions 9a, 11b, 28a through 28d, and 28f:

$$
\left[\frac{\partial P_{D y}}{\partial y_{D}}\right]_{y_{D}=1}=0
$$

These conditions assumed a constant flow rate at $\mathrm{y}_{\mathrm{D}}=0$ and no flow at $\mathrm{x}_{\mathrm{D}}=0, \mathrm{x}_{\mathrm{D}}=1, \mathrm{z}_{\mathrm{D}}=0, \mathrm{z}_{\mathrm{D}}$ $=1$, and $\mathrm{y}_{\mathrm{D}}=1$, respectively. The solved dimensionless pressure $\mathrm{p}_{\mathrm{Dy}}$ - was 


$$
\begin{aligned}
p_{D y}= & u_{y} \sum_{n=0}^{\infty}\left[2 \sqrt{\frac{\tau K_{y}}{\pi}}\left(\exp \left(\frac{\left(2 n+y_{D}\right)^{2}}{4 K_{y} \tau}\right)+\exp \left(\frac{-\left(2 n+2-y_{D}\right)^{2}}{4 K_{y} \tau}\right)\right)\right. \\
& \left.-\left(2 n+y_{D}\right) \operatorname{erfc}\left(\frac{\left(2 n+1-y_{D}\right)}{2 \sqrt{K_{y} \tau}}\right)-\left(2 n+2-y_{D}\right) \operatorname{erfc} \frac{\left(2 n+2-y_{D}\right)}{2 \sqrt{K_{y} \tau}}\right]
\end{aligned}
$$

Based on the principle of superposition, the solution $\mathrm{p}_{\mathrm{D}}$ to Eq. 27 and conditions $9 \mathrm{a}, 11 \mathrm{a}, 11 \mathrm{~b}$, and 28 a through $28 \mathrm{~d}$ was

$$
\mathrm{p}_{\mathrm{D}}=\mathrm{p}_{\mathrm{Dy}}+\mathrm{p}_{\mathrm{Dy}^{-}}
$$

Similar pressure solutions ( $\mathrm{p}_{\mathrm{Dx}}+\mathrm{p}_{\mathrm{Dx}^{-}}, \mathrm{p}_{\mathrm{Dz}}+\mathrm{p}_{\mathrm{Dz}}$ ) to Eq. 27 could be obtained for "1-D" flow in $\mathrm{x}$ and $\mathrm{z}$ directions, respectively. Thus, the solution for Eq. $8 \mathrm{a}$ was

$$
\mathrm{p}_{\mathrm{D}}=\mathrm{p}_{\mathrm{Dx}}+\mathrm{p}_{\mathrm{Dx}^{-}}+\mathrm{p}_{\mathrm{Dy}}+\mathrm{p}_{\mathrm{Dy}^{-}}+\mathrm{p}_{\mathrm{Dz}}+\mathrm{p}_{\mathrm{Dz}^{-}}
$$

The shape factor was calculated using Eq. 2. For the case of a cubic rock matrix with the pressure gradient of $u_{x}, u_{y}$, and $u_{z}$ in $x, y$, and $z$ direction, respectively, the shape factor was

$$
\sigma=\frac{2\left(\mathrm{u}_{\mathrm{x}}+\mathrm{u}_{\mathrm{y}}+\mathrm{u}_{\mathrm{z}}\right)}{\mathrm{a}^{2}\left(\mathrm{p}_{\mathrm{D}, \mathrm{y}=0}-\overline{\mathrm{p}_{\mathrm{D}}}\right) \Delta \mathrm{p}_{0}}
$$

\section{SOLUTIONS FOR CONSTANT FRACTURE PRESSURE FOLLOWED BY LINEARLY DECLINING FRACTURE PRESSURE}

Using Duhamel's theorem and conditions $12 \mathrm{a}$ and $13 \mathrm{a}$, the 1-D diffusivity equation in the $\mathrm{y}$ direction was solved ${ }^{8}$ to obtain

$$
\begin{aligned}
\mathrm{p}_{\mathrm{D}}= & 1-\frac{2}{\mathrm{~b}} \sum_{\mathrm{n}=1}^{\infty} \exp \left(-\mathrm{n}^{2} \mathrm{~K}_{\mathrm{y}} \pi^{2} \tau / \mathrm{b}^{2}\right) \sin \frac{\mathrm{n} \pi \mathrm{y}}{\mathrm{b}}\left\{\int_{0}^{\mathrm{b}} \sin \frac{\mathrm{n} \pi \mathrm{y}^{\prime}}{\mathrm{b}} d \mathrm{y}^{\prime}\right. \\
& \left.+\frac{\mathrm{nK} \mathrm{K} \pi}{\mathrm{b}} \int_{0}^{\tau} \exp \left(\mathrm{n}^{2} \mathrm{~K}_{\mathrm{y}} \pi^{2} \lambda / \mathrm{b}^{2}\right)\left[\Psi_{1}(\lambda)-(-1)^{\mathrm{n}} \Psi_{2}(\lambda)\right] \mathrm{d} \lambda\right\}
\end{aligned}
$$

where $\Psi_{1}$ and $\Psi_{2}$ were boundary conditions at $y=0$ and $y=b$, respectively. When $\Psi_{1}=\Psi_{2}=\kappa^{\prime} \lambda$, this resulted in a solution for the case of constant fracture pressure followed by linearly declining fracture pressure in the 1-D model:

$$
\begin{aligned}
& \mathrm{p}_{\mathrm{D}}=1-\frac{4}{\pi} \sum_{\mathrm{n}=0}^{\infty} \frac{\alpha_{1}}{2 \mathrm{n}+1} \sin (2 \mathrm{n}+1) \pi \mathrm{y}_{\mathrm{D}}+\kappa^{\prime} \frac{\left(\tau-\tau_{0}\right)}{\Delta \mathrm{p}_{0}}+\frac{4 \beta}{\pi} \sum_{\mathrm{n}=0}^{\infty} \frac{\alpha_{2}-1}{(2 \mathrm{n}+1)^{3}} \sin (2 \mathrm{n}+1) \pi \mathrm{y}_{\mathrm{D}} \\
& \text { where } \alpha_{1}=\exp \left[-(2 \mathrm{n}+1)^{2} \mathrm{~K}_{\mathrm{y}} \pi^{2} \tau / \mathrm{b}^{2}\right] \\
& \\
& \left.\qquad \alpha_{2}\right]_{\tau \leq \tau_{0}}=0 \\
& {\left[\alpha_{2}\right]_{\tau>\tau_{0}}=\exp \left[-(2 \mathrm{n}+1)^{2} \mathrm{~K}_{\mathrm{y}} \pi^{2}\left(\tau-\tau_{0}\right) / \mathrm{b}^{2}\right]} \\
& \beta=\frac{\kappa^{\prime} b^{2}}{\mathrm{~K}_{\mathrm{y}} \pi^{2} \Delta \mathrm{p}_{0}}
\end{aligned}
$$


Based on the method of separation of variables, the $\mathrm{p}_{\mathrm{D}}$ solution of Eq. 8a for 3-D flow was:

$$
\begin{aligned}
\mathrm{p}_{\mathrm{D}}=1- & 64 \pi^{3} \sum_{\mathrm{l}=0}^{\infty} \sum_{\mathrm{m}=0}^{\infty} \sum_{\mathrm{n}=0}^{\infty} \frac{\exp (-\mathrm{Ft})}{(2 \mathrm{l}+1)(2 \mathrm{~m}+1)(2 \mathrm{n}+1)} \\
& \cdot \sin (2 \mathrm{l}+1) \pi \mathrm{x}_{\mathrm{D}} \cdot \sin (2 \mathrm{~m}+1) \pi \mathrm{y}_{\mathrm{D}} \cdot \sin (2 \mathrm{n}+1) \pi \mathrm{z}_{\mathrm{D}} \\
+ & \kappa \frac{\left(\tau-\tau_{0}\right)}{\Delta \mathrm{p}_{0}}+\frac{64 \kappa^{\prime}}{\pi^{3} \Delta \mathrm{p}_{0}} \sum_{1=0}^{\infty} \sum_{\mathrm{m}=0}^{\infty} \sum_{\mathrm{n}=0}^{\infty} \frac{\alpha_{2}-1}{(2 \mathrm{l}+1)(2 \mathrm{~m}+1)(2 \mathrm{n}+1) \mathrm{F}} \\
& \cdot \sin (2 \mathrm{l}+1) \pi \mathrm{x}_{\mathrm{D}} \cdot \sin (2 \mathrm{~m}+1) \pi \mathrm{y}_{D} \cdot \sin (2 \mathrm{n}+1) \pi \mathrm{Z}_{\mathrm{D}}
\end{aligned}
$$

The 1-D average dimensionless pressure and flow rates were calculated from $\mathrm{p}_{\mathrm{D}}$ as

$$
\begin{aligned}
& \overline{p_{D}}=1-\frac{8}{\pi^{2}} \sum_{n=0}^{\infty} \frac{\alpha_{1}}{(2 n+1)^{2}}+\kappa^{\prime} \frac{\left(\tau-\tau_{0}\right)}{\Delta p_{0}}+\frac{8 \beta}{\pi^{2}} \sum_{n=0}^{\infty} \frac{\alpha_{2}-1}{(2 n+1)^{4}} \\
& q_{y}=\frac{4 k_{x} a c \Delta p_{0}}{\mu b}\left[\sum_{n=0}^{\infty} \alpha_{1}-\beta \sum_{n=0}^{\infty} \frac{\alpha_{2}-1}{(2 n+1)^{2}}\right]
\end{aligned}
$$

Based on Eq. 2, the 1-D shape factor is

$$
\sigma=\frac{\pi^{2}}{b^{2}} \frac{\sum_{n=0}^{\infty} \alpha_{1}-\beta \sum_{n=0}^{\infty} \frac{\alpha_{2}-1}{(2 n+1)^{2}}}{\sum_{n=0}^{\infty} \frac{\alpha_{1}}{(2 n+1)^{2}}-\beta \sum_{n=0}^{\infty} \frac{\alpha_{2}-1}{(2 n+1)^{4}}}
$$

\section{SOLUTIONS FOR LINEARLY DECLINING FRACTURE PRESSURE FOLLOWED BY CONSTANT FRACTURE PRESSURE}

The diffusivity equation in the y direction subject to boundary conditions 14a and 15a was solved by the same method used in the previous section,

$$
\begin{aligned}
& \mathrm{p}_{\mathrm{D}}=1-\frac{2}{\mathrm{~b}} \sum_{n=0}^{\infty} \alpha_{2} \sin \frac{(2 \mathrm{n}+1) \pi \mathrm{y}}{\mathrm{b}} \int_{0}^{\mathrm{b}} \omega \sin \frac{(2 \mathrm{n}+1) \pi \mathrm{y}^{\prime}}{\mathrm{b}} d \mathrm{y}^{\prime} \\
& \text { where } \omega=\frac{\kappa^{\prime} \tau}{\Delta \mathrm{p}_{0}}+\frac{4 \beta}{\pi} \sum_{\mathrm{m}=0}^{\infty} \frac{\alpha_{1}-1}{(2 \mathrm{~m}+1)^{3}} \sin \frac{(2 \mathrm{~m}+1) \pi \mathrm{y}}{\mathrm{b}}
\end{aligned}
$$

and the shape factor was calculated from Eq. 2 based on $\mathrm{p}_{\mathrm{D}}$ in Eq. 41.

\section{DISCUSSION}

Computer programs were written for calculating dimensionless pressure, flow rates, and shape factors shown in Eqs. 19 through 26 for the constant fracture pressure case, in Eqs. 29 through 33 for the constant flow rate case, and in Eqs. 35 through 42 for the case of combination of constant fracture pressure and declining fracture pressure. The calculation of the infinite series in 
the above equations was considered complete in the program calculation when the series terms contributed to less than $10^{-7}$ of the series.

\section{Constant Fracture Pressure}

The 3-D distributions of dimensionless pressure in a quarter of a rock block are shown in Fig. 1 for $\tau$ of 0.008 and in Fig. 2 for $\tau$ of 0.04 , respectively. The pressure contours are somewhat parallel to the rock surface due to the boundary condition of a constant pressure in the fracture. At the early depletion stage $(\tau=0.008)$ Fig. 1 shows a sharp pressure gradient near the rock surface. More than $90 \%$ of initial pressure was depleted near the fracture, whereas only $10 \%$ pressure depletion occurred halfway from the fracture to the center of the rock matrix. As $\tau$ increased to $0.04,50 \%$ of the pressure was depleted near the center of the rock matrix (Fig. 2).

Figure 3 illustrates the distribution of pressure depletion at different $\tau$ values in a 2-D rock matrix. The pressure depletion spreads from the rock surface to the rock center with the depletion time. At $\tau$ of 0.18 more than $95 \%$ of pressure was depleted everywhere in the rock matrix. The pressure depletion in 2-D rock matrix (Fig. 3) was less than that in 3-D rock matrix (Fig. 2).

The pressure depletion profile in 1-D rock slab (Fig. 4) for $\tau$ values ranged from 0.0002 to 0.78 . The rock pressure depletion was developed from the surface to the center of rock with depletion time. As the $\tau$ value exceeded 0.26 , most pressure was depleted, and a nearly straightline profile was obtained. Compared to the central layer of 2-D and 3-D rock matrix, 1-D rock slab had the lowest pressure depletion profile (Fig. 5). The average pressure depletion within the rock matrix was also the lowest for 1-D rock slab, followed by 2-D rock matrix, at various depletion times (Fig. 6). This was attributed to a faster depletion from six rock surfaces from a 3-D rock matrix than four surfaces from 2-D and two surfaces from 1-D rock matrices.

As shown in Fig. 7, shape factors were calculated at various depletion times using Eqs. 19 through 21 for 3-D and Eq. 22 for 1-D rock matrices. Shape factors for 2-D rock matrices were also included for comparison. Shape factor values were high at the initial depletion stage under unsteady-state production. As depletion proceeded, the shape factor converged to $\pi^{2} / \mathrm{L}^{2}, 2 \pi^{2} / \mathrm{L}^{2}$, and $3 \pi^{2} / L^{2}$ for $1-, 2-$, and 3-D rock matrix, respectively, at $\tau$ value of about 0.1 . The increase in shape factor values with the number of sets of normal fractures was in agreement with the number of depletion surfaces of the rock matrix. The $\tau$ value of 0.1 ranged from less than 1 day for commonly encountered fractured reservoirs to months for large and tight fractured rock.

The equivalent depth, $\Delta \mathrm{L}$, where the average rock pressure was located in the rock matrix from the fracture surface, was calculated using the shape factor value and Eq. 5. The corresponding $\Delta \mathrm{L}$ to shape factor $\pi^{2} / \mathrm{L}^{2}$ during QSS was $0.2 \mathrm{~L}$. This $\Delta \mathrm{L}$ value was less than $0.5 \mathrm{~L}$ assumed by Kazemi and $0.25 \mathrm{~L}$ associated with Coats's shape factor. For shape factor values greater than $\pi^{2} / \mathrm{L}^{2}$ at the initial depletion stage $(\tau<0.1)$, the $\Delta \mathrm{L}$ value was less than $0.2 \mathrm{~L}$. This can be seen in Fig. 4 from the sharper pressure gradient at the early depletion than the late depletion stage.

The rock matrix flow declined with time because of the decline of average pressure in the rock (Fig. 8). It showed a linear decline for the rock pressure with time in a semi-log plot. Initially, the matrix flow declined sharply at the transient stage for $\tau$ value less than 0.1 . The flow then declined linearly with $\tau$ in a semi-log plot, showing a slope of $-4,-8$, and -12 for $1-, 2-$, and 3-D flow rock matrix, respectively (Fig. 9). These decline slopes might be used to distinguish the number of normal sets of fractures associated with the rock matrix. By matching the production history of a fractured rock in a semi-log plot with Fig. 9, the size (length) of the rock matrix can be 
calculated by comparing production time with the value of matched dimensionless time when other rock-fluid properties in Eq. 14 are known.

Figure 10 shows the $\log$-log plot of flow rates with dimensionless time $\tau$. Compared to 1 and 2-D flow rates, the 3-D flow was higher at the transient stage and lower at QSS due to a faster pressure depletion. The slope value of -0.5 in the transient stage (Fig. 10) was characteristic to the linear flow between the rock matrix and the fracture. When the $\tau$ value exceeded 0.1 , flow rates declined exponentially at different rates for 1-, 2-, and 3-D flow.

\section{Constant Flow Rate}

When the flow rate between the rock matrix and the fracture was constant, the fracture pressure varied with location on the rock surface (Figs. 11-12). Figure 11 displays a quarter of the 3-D dimensionless pressure distribution at different cross sections for $\tau$ of 0.032 . The top or surface layer $\left(z_{D}=0\right)$ showed higher pressure depletion than the central layer $\left(z_{D}=0.5\right)$ and the inside layer (e.g. $\mathrm{zD}_{\mathrm{D}}=0.25$ ). High pressure depletion occurred in the diagonal direction in the rock matrix due to the combination of flow at the junction of two sets of fractures. Similar distribution patterns of $\mathrm{p}_{\mathrm{D}}$ in Fig. 11 were obtained for $\tau$ of 0.158 in Fig. 12. As expected, the p values in Fig. 12 are greater than those in Fig. 11 due to a longer depletion time.

Figure 13 shows the distributions of $\mathrm{p}_{\mathrm{D}}$ for 2-D flow rates at three different depletion times. The distribution pattern in Fig. 13 is similar to that of the 3-D flow case in Figs. 11 and 12. The $\mathrm{p}_{D}$ value increased with time without a limit for the case of constant flow rate at the rock surface. The $\mathrm{p}_{D}$ value reached 16 for $\tau$ value of 4 . The $\mathrm{p}_{\mathrm{D}}$ distributions for 1-D flow from a rock slab, illustrated in Fig. 14, had similar profiles at various depletion times. For examining $\mathrm{p}_{\mathrm{D}}$ at the early stage $p_{D}$ profiles were shown in a semi-log plot in Fig. 15.

The average pressure drop of rock matrix increased linearly with time as plotted in a log-log scale (Fig. 16) and in a linear scale (Fig. 17).

Based on the average fracture pressure, shape factors (Fig. 18) were calculated using Eq. 29. Similar to that for constant fracture pressure, the shape factor in Fig. 18 started at a high value and decreased with production time until a $\tau$ value of 0.1 was reached. The shape factor values converging at 0.1 were $12 / \mathrm{L}^{2}, 24 / \mathrm{L}^{2}$, and $36 / \mathrm{L}^{2}$, for one-, two-, and three-dimensional rock matrix flow, respectively. After reaching QSS the shape factors calculated from the case of constant flow rate were 1.2 times those from the case of constant fracture pressure (Fig. 19). The corresponding $\Delta \mathrm{L}$ for shape factor $12 / \mathrm{L}^{2}$ at QSS was $0.167 \mathrm{~L}$.

\section{Constant Fracture Pressure Followed by Linearly Declining Fracture Pressure}

For illustration, $\Delta \mathrm{p} 0$ of $10 \mathrm{psi}$, to of 0 , and $\kappa^{\prime}$ of $1 \mathrm{psi} /$ day were used for calculating $\mathrm{p}_{\mathrm{D}}$ in Eq. 35. Figure 20 shows these pD profiles at various depletion times. Because of the initial pressure drawdown assigned at the fracture, the pD profile at the early time $(\tau=0.002)$ was similar to that in the case of constant fracture pressure shown in Fig. 4. As the depletion time proceeded, the pressure declining at the fracture resulted in a higher pressure drop throughout the rock in Fig. 20 compared to that in Fig. 4. To display pD values at longer depletion times Fig. 20 was replotted in the semi-log scale in Fig. 21. When the dimensionless depletion time $\tau$ exceeded 0.01 , the pD profiles were similar to those depleted at a constant flow rate shown in Fig. 15.

The histories of the flux rate per unit pressure (psi) drop and the average $p_{D}$ of the rock matrix are shown in log-log scales in Fig. 22. The flux rate declined at an initial slope of 0.5 when the value of dimensionless time was less than 0.04 , matching the early declining behavior for the case of constant fracture pressure (Fig. 10). This indicated that the early depletion behavior in Fig. 
22 was dominated by the constant pressure assigned at the fracture. When the $\tau$ value was greater than 1 , the flux rate converged to a constant value. The linearly declining pressure in this case resulted in a constant flux or flow rate at the later depletion time. This corresponded to the case of the constant flow rate condition which resulted in a linearly declining fracture pressure. Thus, the boundary condition of a constant fracture pressure followed by a linearly declining fracture pressure is equivalent to a combination of conditions of a constant fracture pressure at the early time and a constant flow rate at the late depletion time.

The time-dependent shape factor for the studied example is shown in Fig. 23. Having declined with time, the shape factors had similar values to those of constant fracture pressure for $\tau$ value less than 0.04 . The shape factor value increased slightly from about $\pi^{2} / \mathrm{L}^{2}$ to $12 / \mathrm{L}^{2}$ for $\tau$ value greater than 0.04 . The shape factor values at the late stage agreed well with those calculated based on the constant flow rate condition.

\section{Linearly Declining Fracture Pressure Followed by Constant Fracture Pressure}

For the illustration case study, the fracture pressure was assumed to decline at a rate of 1 psi/day for 10 days before the fracture pressure was set at a constant value of 10 psi below the initial rock pressure. As shown in Fig. 24 , the shape factor value converged to $12 / \mathrm{L}^{2}$ before the fracture pressure was fixed after 10 days of depletion (or a $\tau$ value of 1.6). The shape factor value then decreased slightly from $12 / \mathrm{L}^{2}$ to $\pi^{2} / \mathrm{L}^{2}$ in response to the switch of the boundary condition from the constant flow rate to the constant fracture pressure.

\section{Comparison of Shape Factors}

After reaching QSS, shape factors calculated from the case of constant flow rate were 1.2 times those from the case of constant fracture pressure. Subject to the production condition, fluid flow between the rock matrix and the fracture might be between the cases of constant fracture pressure and constant flow rate. Thus, the shape factor at QSS might be between $N \pi^{2} / \mathrm{L}^{2}$ and $12 \mathrm{~N} / \mathrm{L}^{2}$, depending on the dominant flow condition.

The shape factor values calculated from the unsteady-state production were higher than those proposed by Kazemi and by Coats, but less than or equal to those by Warren and Roots. For 1-D rock slab flow at QSS, as an example, the shape factor obtained in this study was $\pi^{2} / L^{2}$ for the constant fracture pressure case and $12 / \mathrm{L}^{2}$ for the constant rate case, in comparison to $4 / \mathrm{L}^{2}$, $8 / \mathrm{L}^{2}$, and $12 / \mathrm{L}^{2}$ used by Kazemi, Coats, and Warren and Roots, respectively. Table 1 compares shape factors obtained from different sources.

TABLE 1

Comparison of shape factors.

$\sigma \mathbf{L}^{2}$

\begin{tabular}{|c|c|c|c|c|c|c|}
\hline $\begin{array}{l}\text { Warren } \\
\& \text { Roots } \\
\end{array}$ & $\begin{array}{l}\text { Kazemi } \\
\text { et al. }\end{array}$ & $\begin{array}{l}\text { Peaceman } \\
\text { et al. }\end{array}$ & $\begin{array}{l}\text { Thomas } \\
\text { et al. }\end{array}$ & $\begin{array}{l}\text { Ueda } \\
\text { et al. }\end{array}$ & Coats & de Swaan \\
\hline 12 & 4 & 12 & - & 8 & 8 & 12 \\
\hline 32 & 8 & 14.23 & -- & 24 & 16 & -- \\
\hline 60 & 12 & 16.53 & 25 & -. & 24 & 60 \\
\hline
\end{tabular}




\section{$\sigma \mathbf{L}^{2}$}

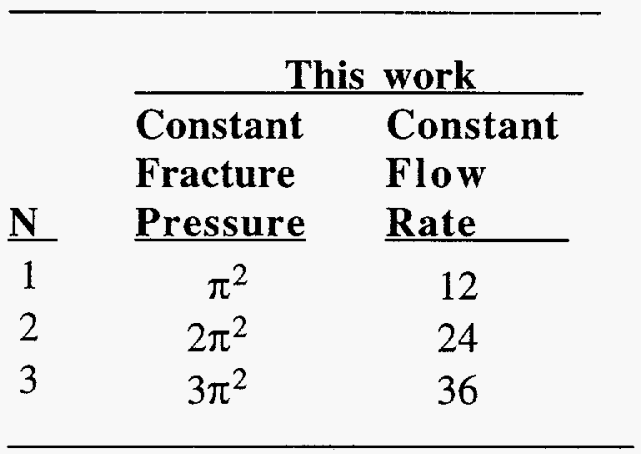

The shape factors of Warren and Roots had the highest values among the equations developed in the Cartesian coordinate, whereas the basis of their shape factors was not clearly explained. ${ }^{1}$ Shape factors derived in cylindrical and spherical coordinates based on material balance and Darcy flow at QSS (see Appendix) happened to show similar forms to Warren and Roots's shape factors:

$$
\begin{array}{ll}
\sigma=15 / \mathrm{r}^{2}=60 / \mathrm{d}_{\mathrm{i}}^{2} & \text { for spherical flow } \\
\sigma=8 / \mathrm{r}^{2}=32 / \mathrm{d}_{\mathrm{i}}^{2} & \text { for cylindrical flow } \\
\sigma=12 / \mathrm{d}^{2} & \text { for linear flow }
\end{array}
$$

Equations 43 through 45 agree with Eq. 6 if $d_{i}$ 's in Eqs. 43 through 45 can be replaced by L. The equivalent location of $\overline{\mathrm{p}_{\mathrm{m}}}$ from the edge of rock matrix were back-calculated to be $0.1 \mathrm{~d}, 0.125 \mathrm{~d}$, and $0.167 \mathrm{~d}$ for $\Delta \mathrm{L}$ in Eq. 43,44 , and 45 , respectively. These values of $\overline{\mathrm{p}_{\mathrm{m}}}$ location were less than the assumption of $0.5 \mathrm{~d}$ in Kazemi's Eq. and most $\Delta \mathrm{L}$ 's solved from diffusivity equation under unsteady-state production.

\section{CONCLUSIONS}

The following conclusions were drawn from this study for the unsteady flow of a slightly compressible single-phase fluid from a rock matrix.

1. Shape factor values are time-dependent under the unsteady-state condition. The shape factor decreases with depletion time in the transient stage and converges to a constant value in QSS at a $\tau$ value of 0.1 . Except for large and tight fractured rock, the period of $\tau$ of 0.1 is less than 1 day for commonly encountered fractured reservoirs; therefore, using a shape factor value based on QSS is a decent approximation.

2. When the fracture pressure is constant, the shape factor converges to $N \pi^{2} / L^{2}$ for $N$-dimensional flow in the rock matrix.

3. When the flow rate between the rock matrix and the fracture is constant, the fracture pressure varies with location on the rock surface. Based on the average fracture pressure, the shape factor converges to $12 \mathrm{~N} / \mathrm{L}^{2}$ for $\mathrm{N}$-dimensional rock matrix flow. 
4. After reaching QSS, the shape factors calculated from the case of constant flow rate are 1.2 times those from the case of constant fracture pressure. The shape factor values calculated from unsteady-state production are higher than those proposed by Kazemi and by Coats, but less than or equal to those by Warren and Roots.

5. The 1-D shape factor values at QSS are between $\pi^{2} / \mathrm{L}^{2}$ and $12 / \mathrm{L}^{2}$ when the rock matrix is produced at a constant fracture pressure followed by or following a constant flow rate.

\section{ACKNOWLEDGMENTS}

The author appreciates the financial support of the U. S. Department of Energy through Cooperative Agreement DE-FC22-83FE60149. The author also gratefully acknowledges Dr. Albert Reynolds and Dr. Ekrem Kasap of the University of Tulsa for their counsel in performing this work. Special thanks are due to Drs. Tom Burchfield, Michael Madden, and Min Tham of the National Institute for Petroleum and Energy Research and Thomas Reid, the project manager of Department of Energy for their reviews of this report.

\section{NOMENCLATURE}

$\mathrm{a}, \mathrm{b}, \mathrm{c},=$ length of rock matrix in $\mathrm{x}, \mathrm{y}$, and $\mathrm{z}$ direction, respectively

$c_{t}=$ compressibility

$\mathrm{d}_{\mathrm{i}}=$ diameter of the spherical or cylindrical matrix

$\mathrm{k}=$ permeability of rock matrix

$\mathrm{K}=$ coefficient defined in $(8 \mathrm{~b})$

$\mathrm{L}=$ length of rock matrix

$1, \mathrm{~m}, \mathrm{n}=$ integer number

$\mathrm{N}=$ number of normal sets of fractures

$\mathrm{p}=$ pressure

$\overline{\mathrm{p}_{\mathrm{m}}}=$ volumetric average pressure of rock matrix block

$\mathrm{q}=$ flow rate between fracture and rock matrix

$\mathrm{r}=$ radius

$\mathrm{r}_{\mathrm{e}}=$ outside radius of the spherical or cylindrical rock matrix

$\mathrm{t}=$ time

$\mathrm{u}_{\mathrm{x}}, \mathrm{u}_{\mathrm{y}}, \mathrm{u}_{\mathrm{z}}=$ constant pressure gradient in $\mathrm{x}, \mathrm{y}$, and $\mathrm{z}$ direction, respectively

$\mathrm{V}=$ bulk volume of rock matrix block

$\mu=$ fluid viscosity

$\sigma=$ shape factor

$\tau$ or $\mathrm{t}_{\mathrm{D}}=$ dimensionless time, defined in Eq. 14

$\phi=$ rock porosity

$\rho=$ density

$\kappa=$ pressure declining rate

$\pi=3.14159 \ldots$.

$\gamma_{1}, \gamma_{2}=$ defined by Eqs. 24 and 25, respectively

$\alpha_{1}, \alpha_{2}, \beta=$ defined by Eqs. 36a through $36 \mathrm{e}$, respectively

Subscripts:

$\mathrm{D}=$ dimensionless term

$\mathrm{f}=$ fracture

$\mathrm{i}=$ initial condition 
$\mathrm{m}=$ rock matrix

$\mathrm{x}, \mathrm{y}, \mathrm{z}=$ Cartesian coordinates

\section{REFERENCES}

1. Warren J. E. and P. J. Root, The Behavior of Naturally Fractured Reservoirs, SPEJ, Sept. 1963 , p. 245-255.

2. Kazemi, H., L. S. Merrill, Jr., K. L. Porterfield, and P. R. Zeman, Numerical Simulation of Water-Oil Flow in Naturally Fractured Reservoirs, SPEJ, Dec. 1976, p. 317-326.

3. Peaceman, D. W., Convection in Fractured Reservoirs - The Effect of Matrix-Fissure Transfer on the Instability of a Density Inversion in a Vertical Fissure, SPEJ, Oct. 1976, p. 269-280.

4. Thomas, L. K., T. N. Dixson, and R. G. Pierson, Fractured Reservoir Simulation, SPEJ, Feb. 1983 , p. $42-54$.

5. Ueda, Y., S. Murata, Y. Watanabe, and K. Funatsu, Investigation of the Shape Factor Used in the Dual-Porosity Reservoir Simulator. SPE paper 19469 presented at the SPE Asia-Pacific Conference in Sydney, Australia, Sept. 13-15, 1989.

6. Coats, K. H., Implicit Compositional Simulation of Single-Porosity and Dual-Porosity Reservoirs, SPE paper 18427 presented at the SPE Symposium on Reservoir Simulation in Houston, TX, Feb. 6-8, 1989.

7. de Swaan, A., Influence of Shape and Skin of Matrix-Rock Blocks on Pressure Transients in Fractured Reservoirs. SPE Formation Evaluation, Dec. 1990, p.344-352.

8. Carslaw, H. S. and J. C. Jaeger, Conduction of Heat in Solids, Oxford University Press, London, 1959.

\section{APPENDIX}

For the spherical flow, we have following material balance equation:

$$
\partial(q \mu)=4 \pi r^{2} \phi\left(\frac{\partial \rho}{\partial t}\right) \partial r
$$

in which

$$
\begin{array}{ll}
\text { Darcy law: } & \mathrm{q}=\frac{4 \pi r^{2} k}{\mu} \frac{\mathrm{dp}}{\mathrm{dr}} \\
\text { compressibility: } & c_{t}=\frac{1}{\rho} \frac{\mathrm{d} \rho}{\mathrm{dp}}
\end{array}
$$

and QSS condition: $\quad \frac{\mathrm{dp}}{\mathrm{dt}}=-\frac{\mathrm{q}}{\mathrm{c}_{\mathrm{t}} \pi \mathrm{r}_{\mathrm{e}}^{2} h \phi}$

are incorporated to give

$$
\frac{1}{r^{2}} \frac{\partial}{\partial r}\left(r^{2} \frac{\partial p}{\partial r}\right)=\frac{\mu}{k}\left(\frac{3 q}{4 \pi r_{\mathrm{e}}^{3}}\right)
$$


Eq. A5 is solved for $p$ as

$$
\mathrm{p}=\mathrm{p}_{\mathrm{r}=0}+\left(\frac{\mathrm{q} \mu \mathrm{r}^{2}}{8 \pi \mathrm{kr}_{\mathrm{e}}^{3}}\right)
$$

And the average rock pressure is obtained by

$$
\overline{\mathrm{p}}=\frac{\int_{0}^{\mathrm{r}_{\mathrm{e}}} \mathrm{p} \partial \mathrm{V}}{\int_{0}^{\mathrm{r}_{\mathrm{e}}} \partial \mathrm{V}}=\mathrm{p}_{\mathrm{r}=0}+\frac{3 q \mu}{40 \pi \mathrm{kr}_{\mathrm{e}}}
$$

Thus, shape factor can be calculated using Eq. 2 to give

$$
\sigma=\frac{15}{r_{\mathrm{e}}^{2}}=\frac{60}{d_{i}^{2}}
$$

Similar procedures can be used to derive shape factors of $32 / \mathrm{d}_{\mathrm{i}}{ }^{2}$ and $12 / \mathrm{d}^{2}$ for cylindrical and linear flow, respectively. 


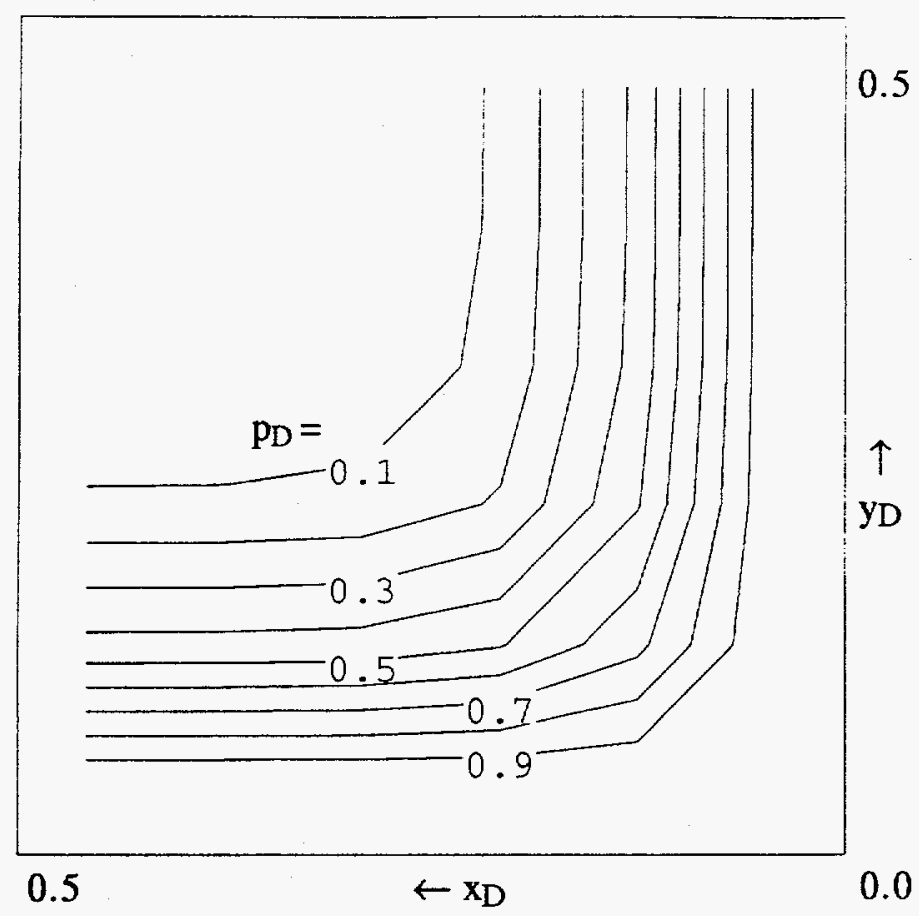

(a) $\mathrm{z}_{\mathrm{D}}=0.5$, central layer

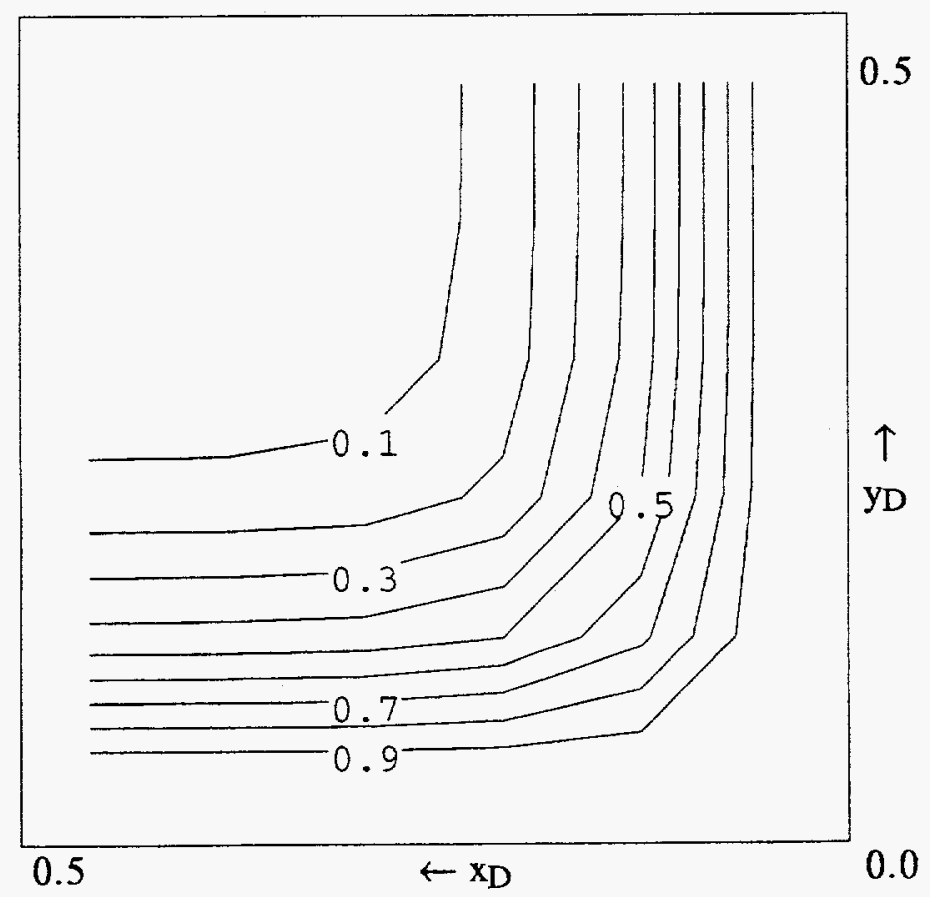

(b) $\mathrm{z}_{\mathrm{D}}=0.3$

Figure 1. - 3-D dimensionless pressure drawdown for constant fracture pressure $\left(\mathrm{tD}_{\mathrm{D}}=0.008\right)$ 


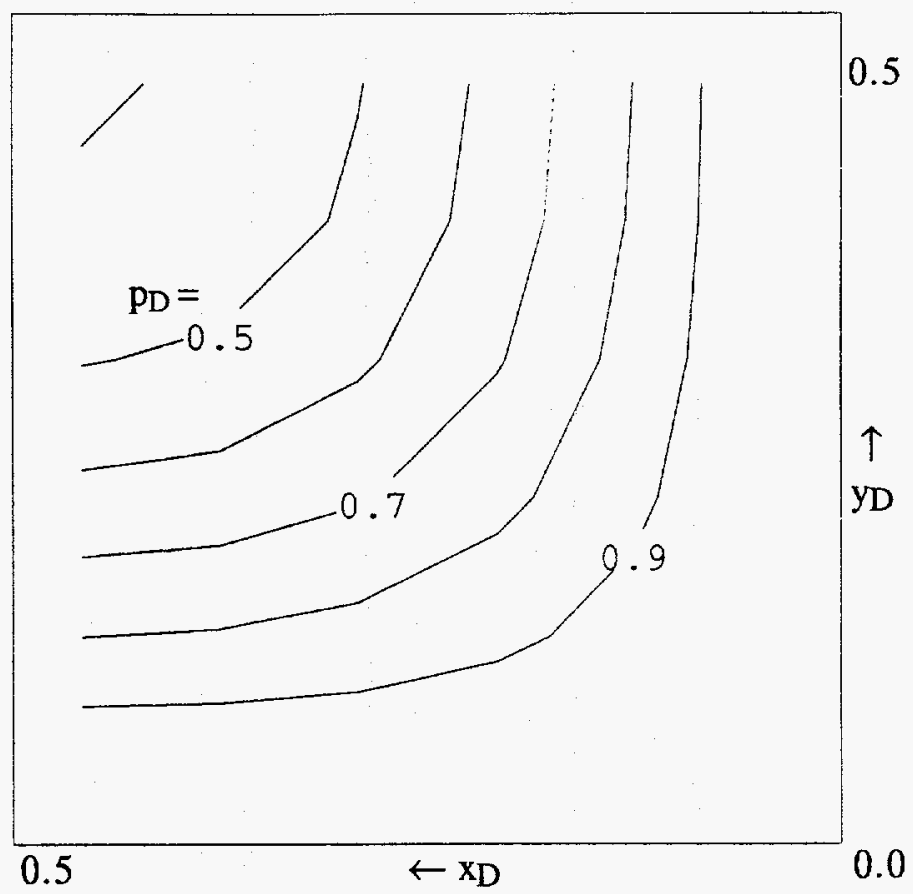

(a) $\mathrm{z}_{\mathrm{D}}=0.5$, central layer

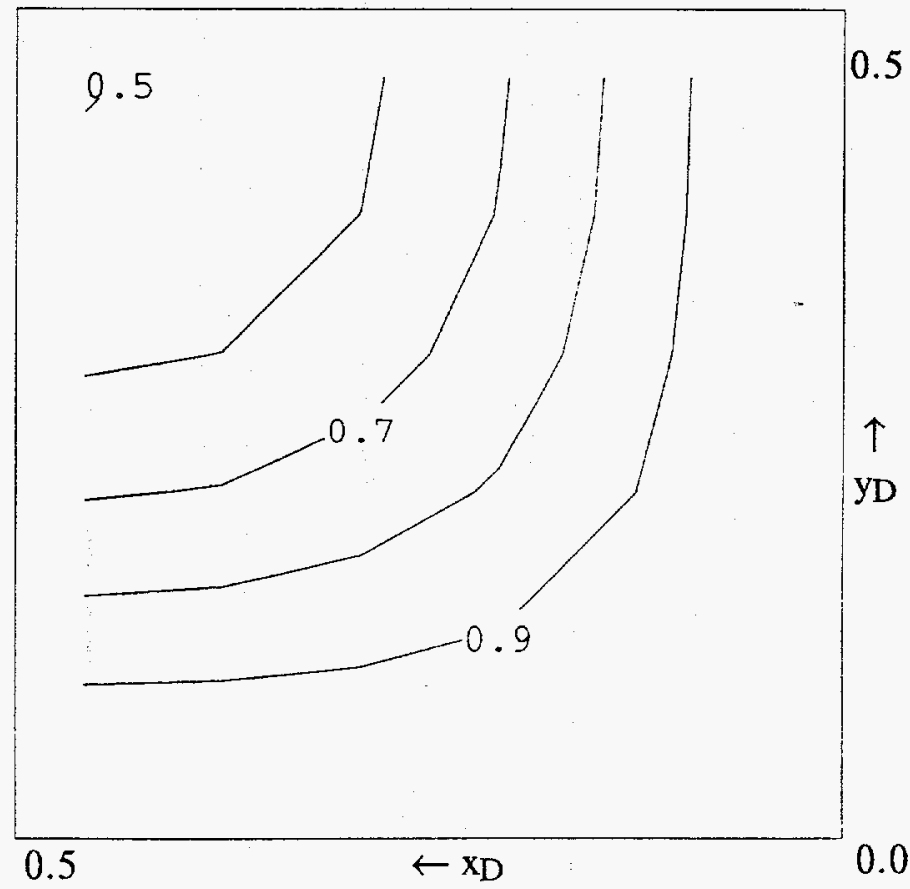

(b) $\mathrm{z}_{\mathrm{D}}=0.3$

Figure 2. - 3-D dimensionless pressure drawdown for constant fracture pressure $\left(t_{D}=0.04\right)$ 


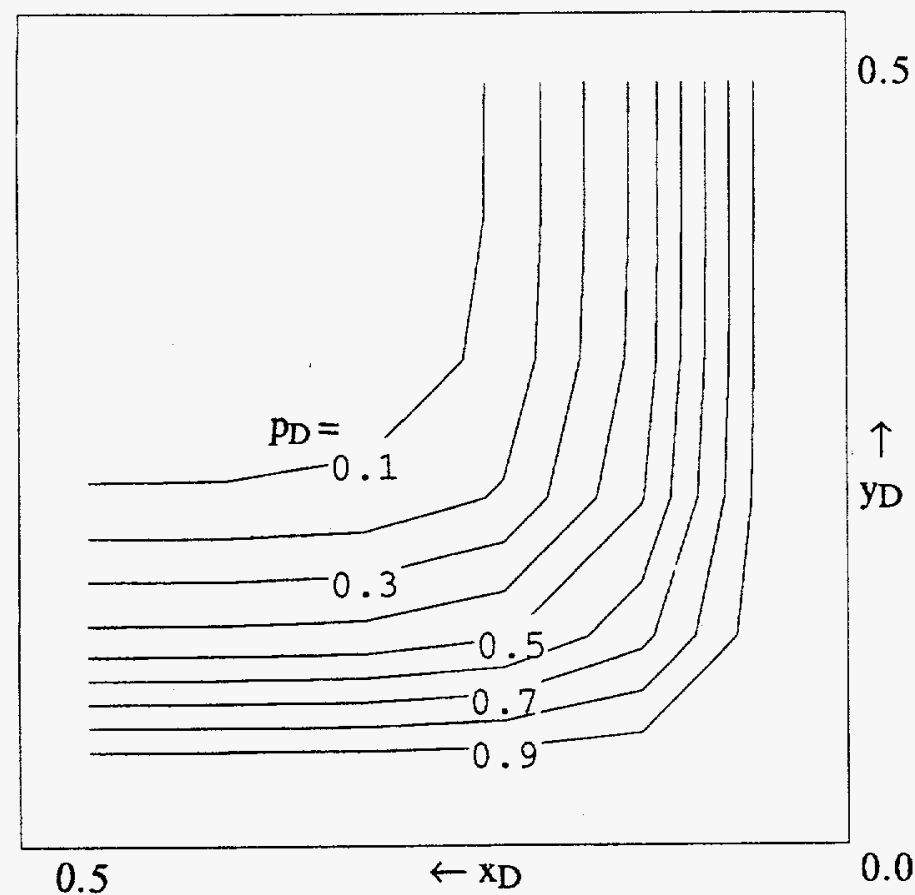

(a) $t_{D}=0.008$

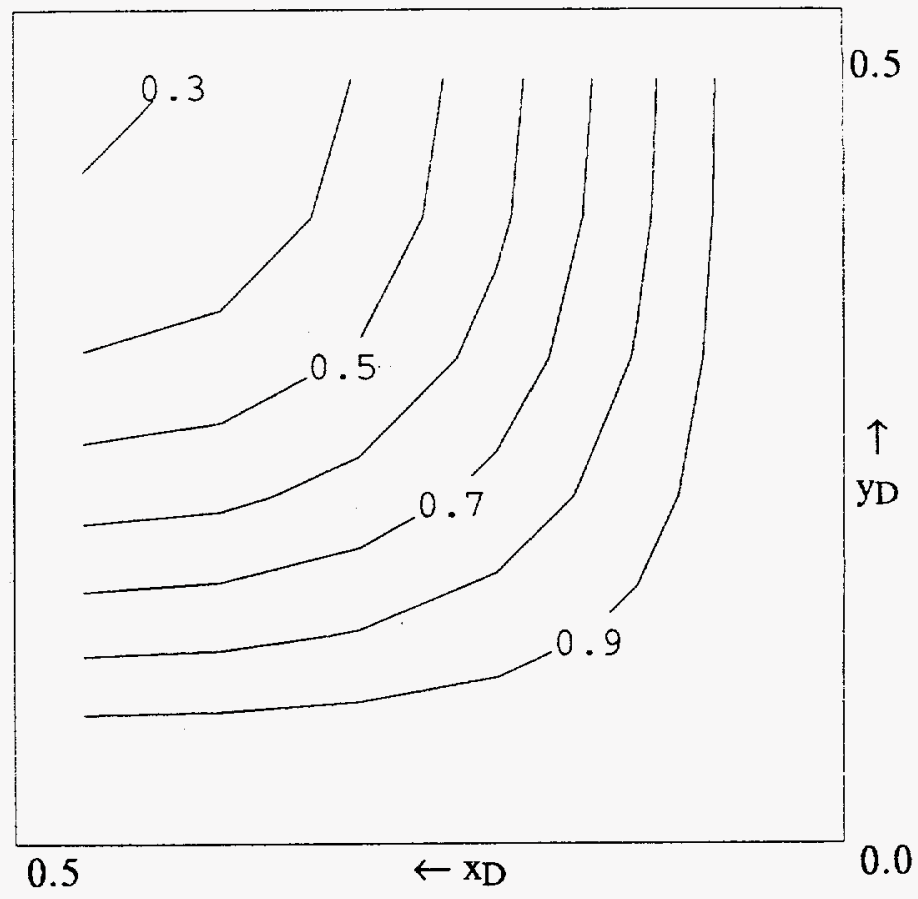

(b) $t_{D}=0.04$

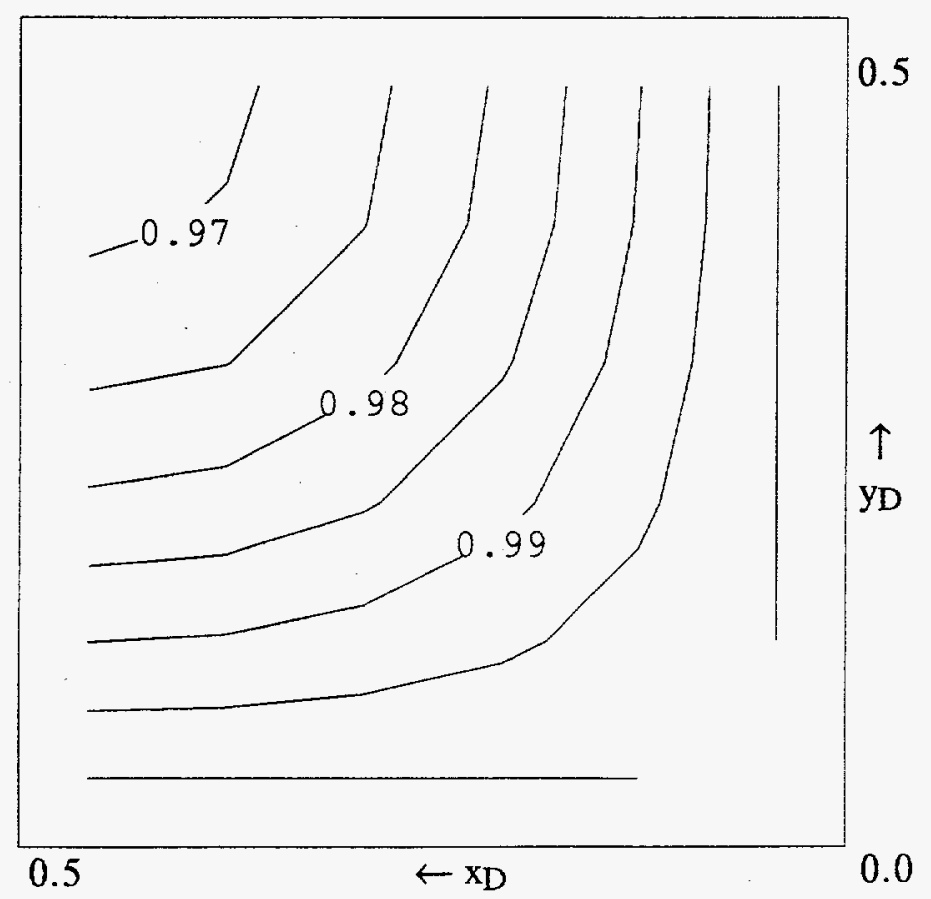

(c) $t_{D}=0.18$

Figure 3. - 2-D dimensionless pressure drawdown for constant fracture pressure 


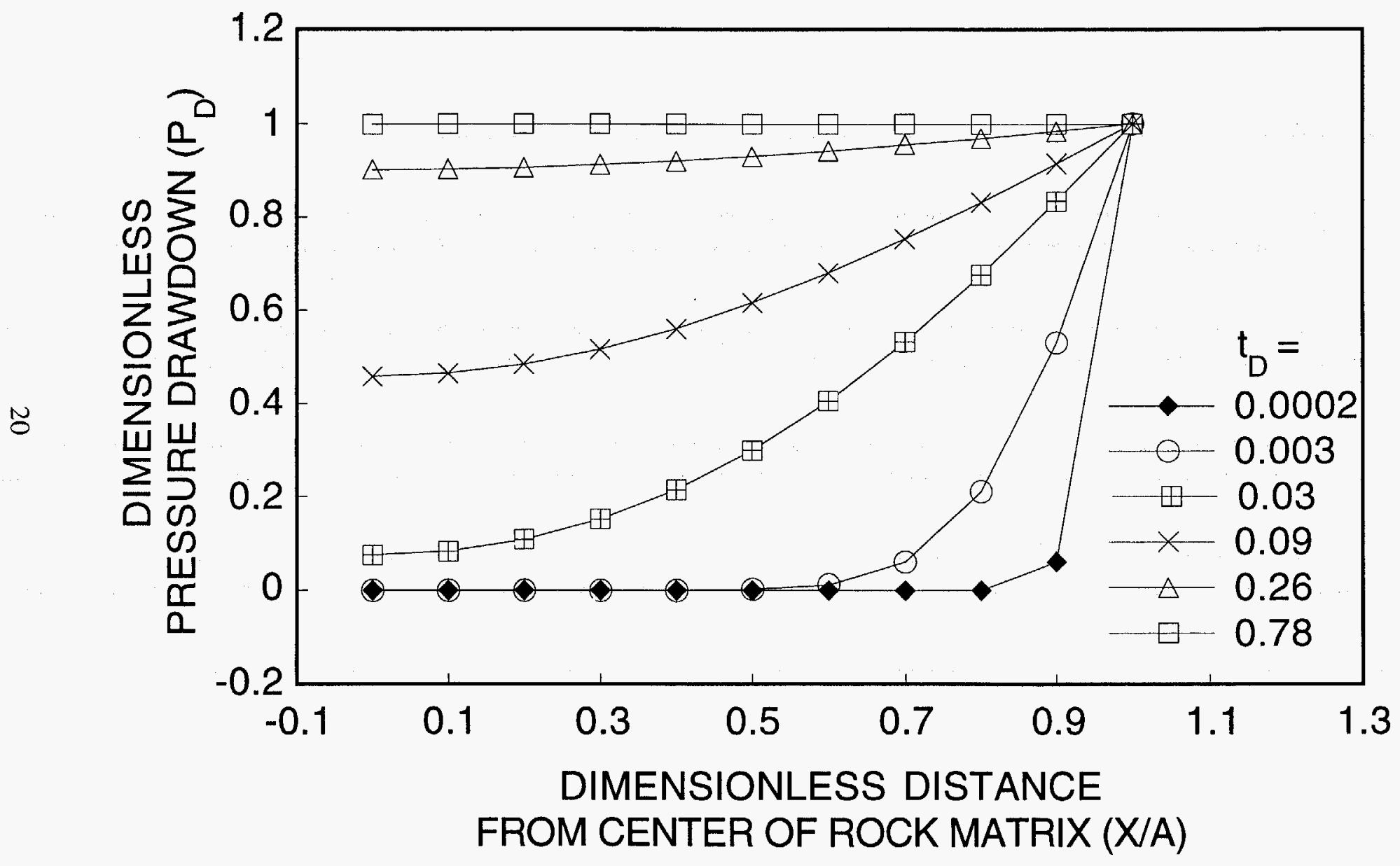

Figure 4. - 1-D dimensionless pressure drawdown for constant fracture pressure 


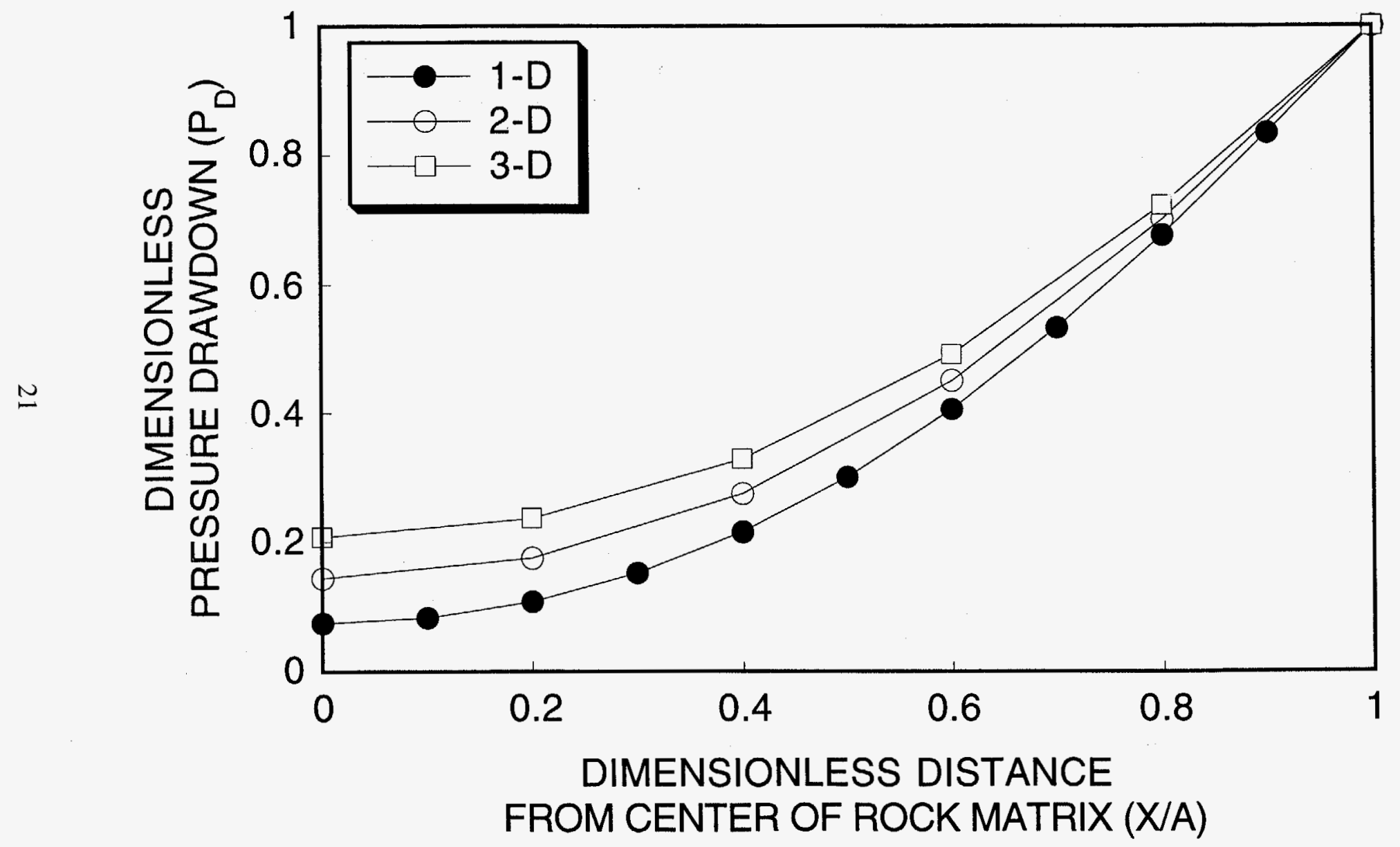

Figure 5. - Average dimensionless pressure drawdown of central layer for constant fracture pressure $\left(t_{D}=0.03\right)$ 


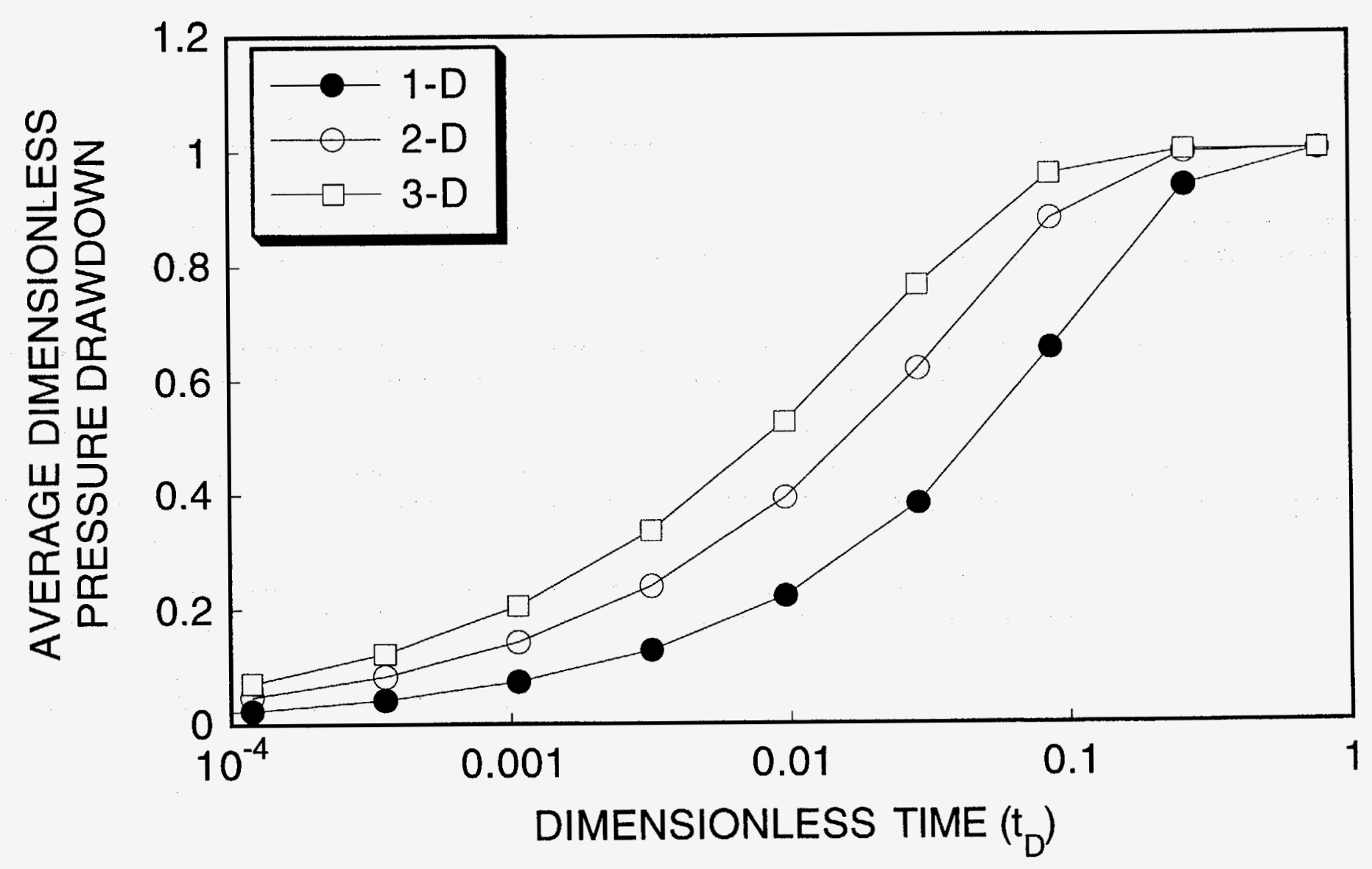

Figure 6. - History of average dimensionless pressure drawdown for constant fracture pressure 


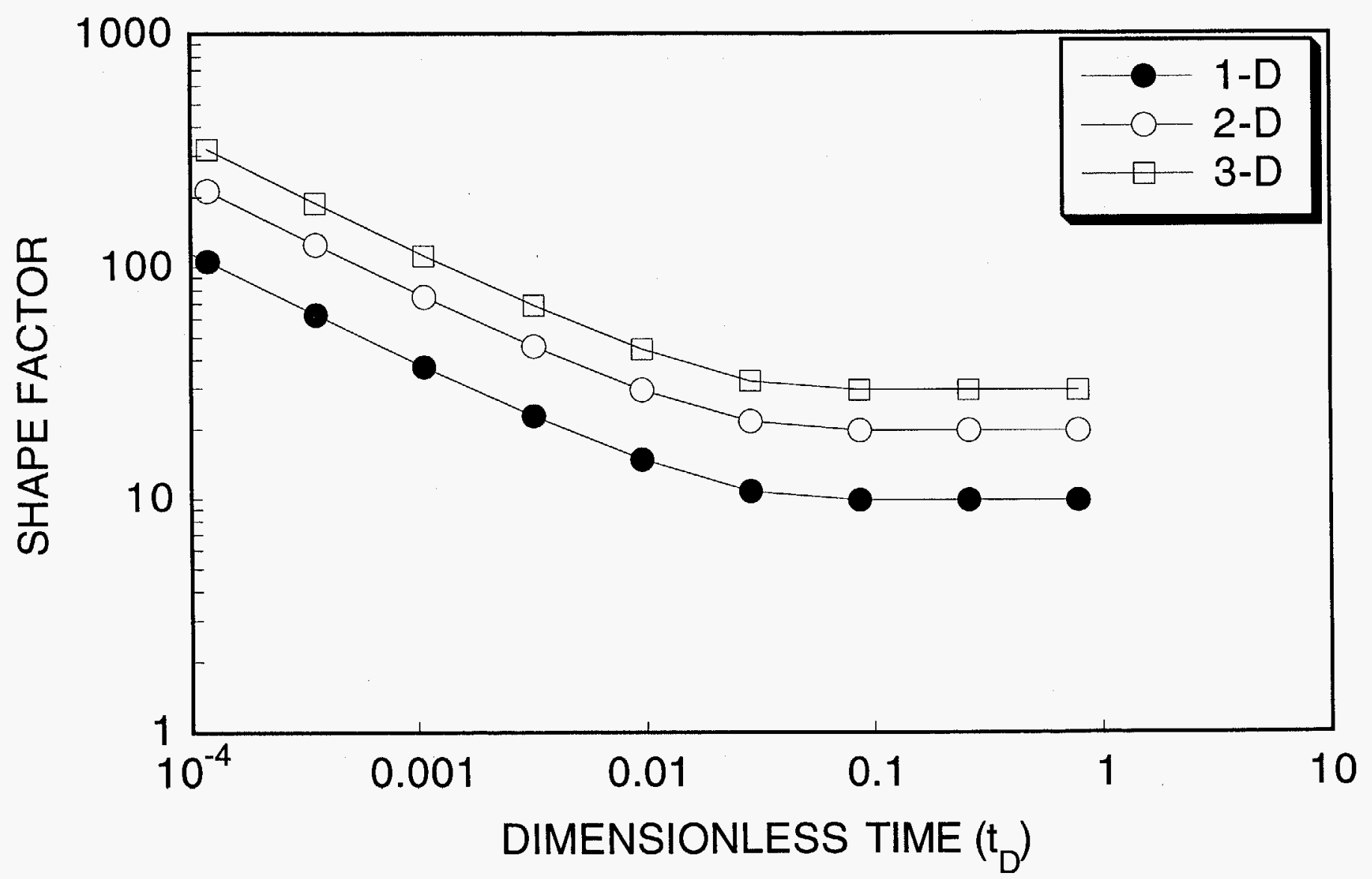

Figure 7. - Shape factors with depletion time for constant fracture pressure 


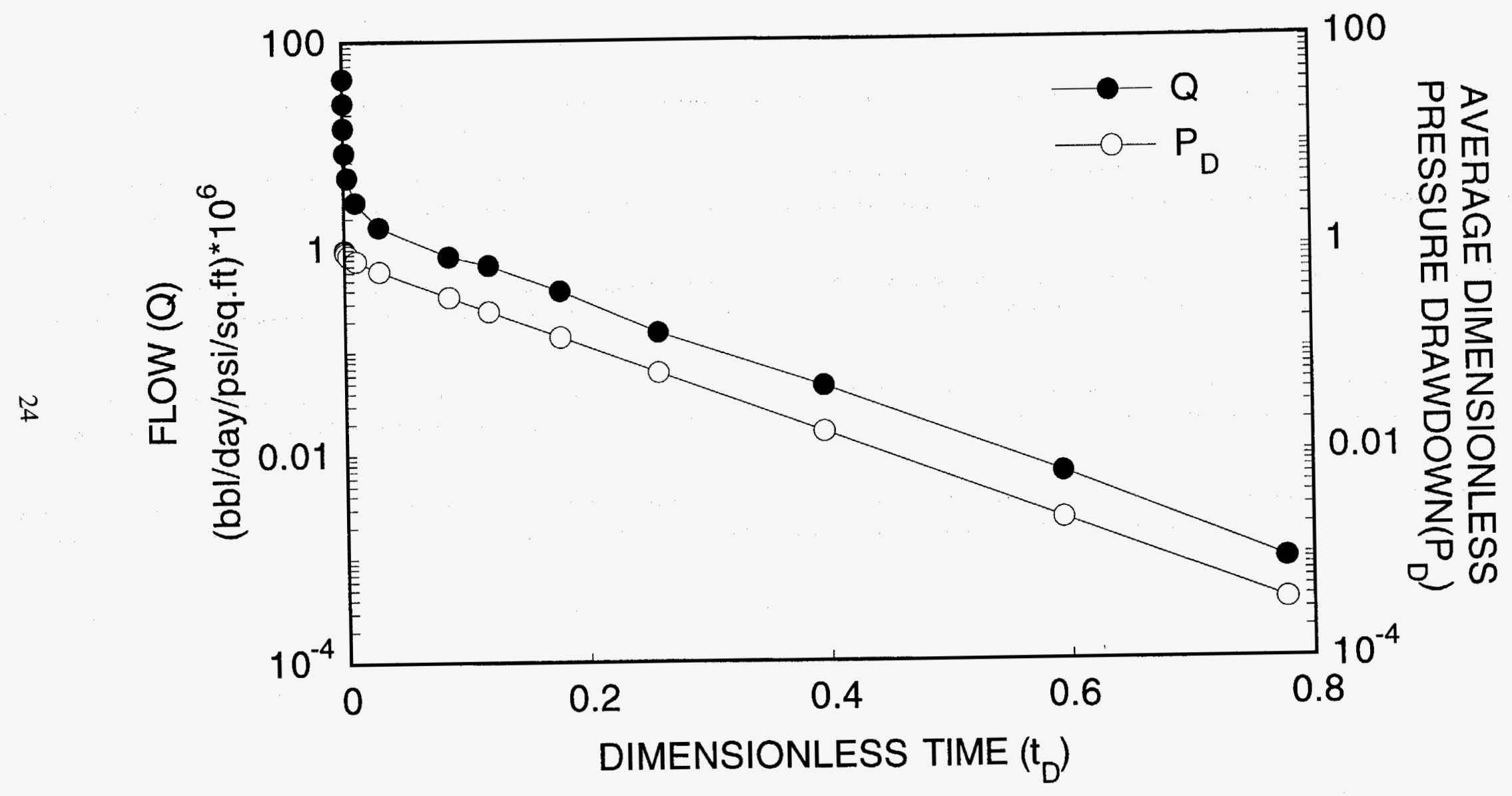

Figure 8. - History of flow rate and Average dimensionless pressure drawdown for constant fracture pressure 


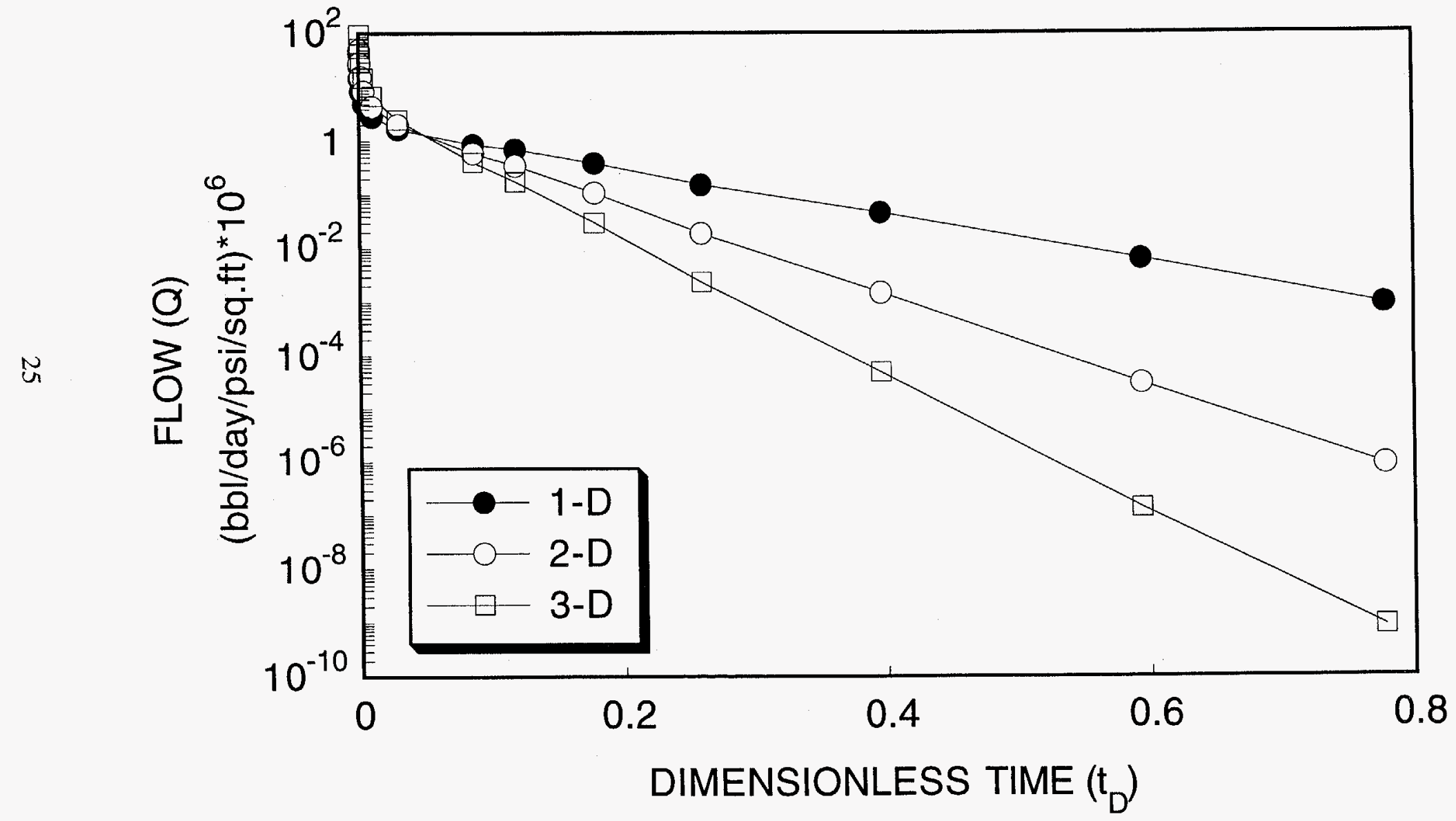

Figure 9. - Flow rate with depletion time (semilog plot) for constant fracture pressure 


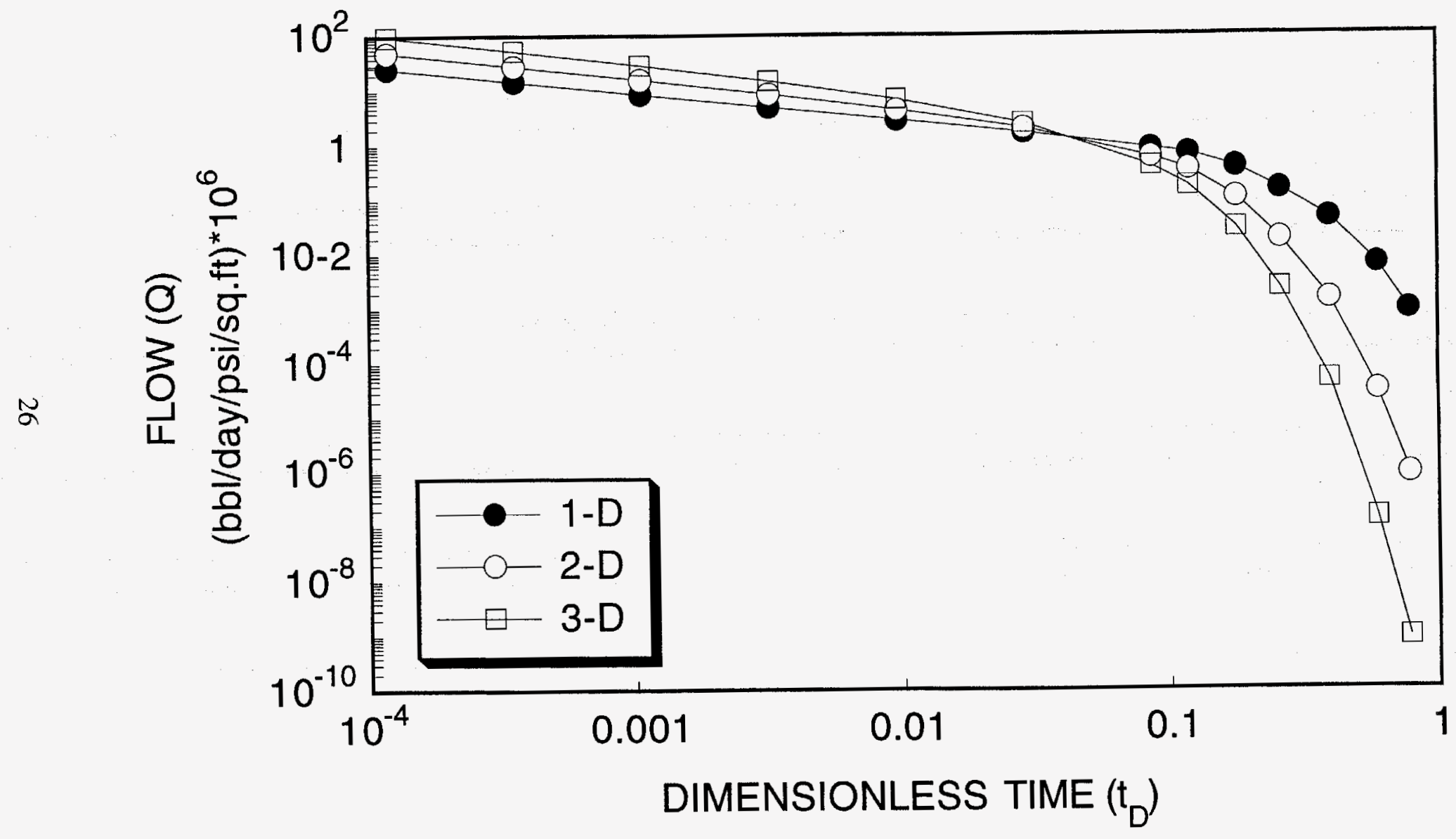

Figure 10. - Flow rate with depletion time (log-log plot) for constant fracture pressure 


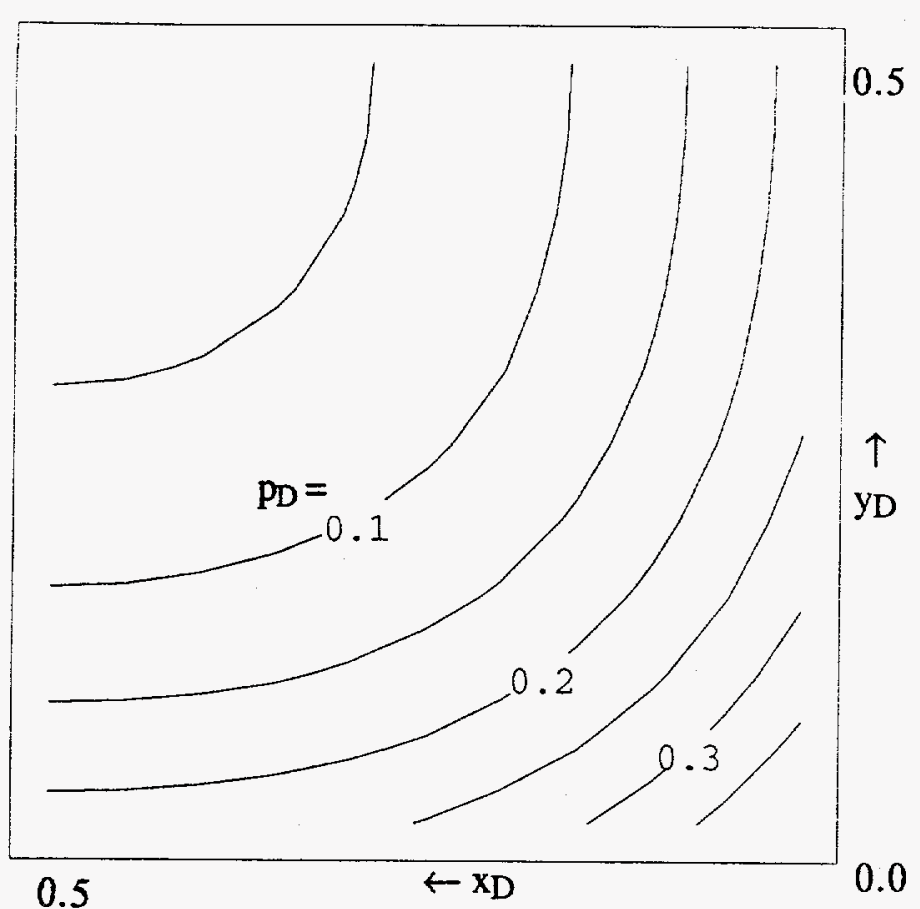

(a) $\mathrm{z}_{\mathrm{D}}=0.5$, central layer

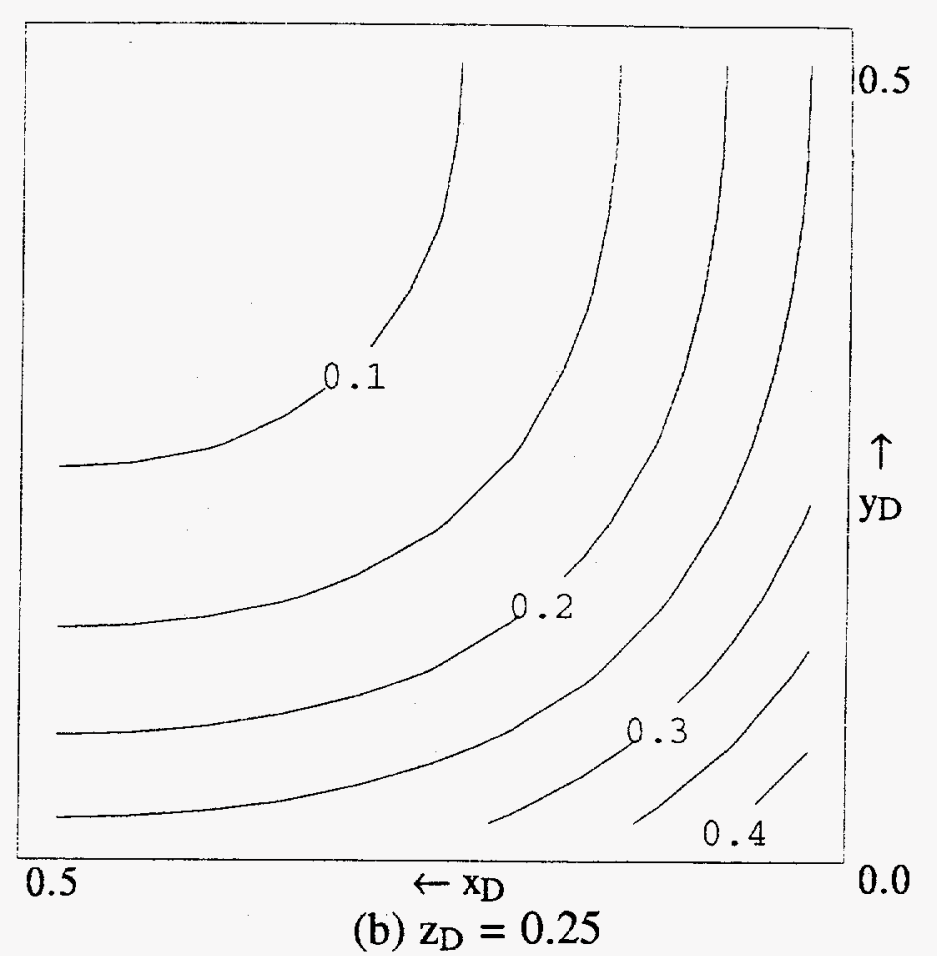

(b) $\mathrm{z}_{\mathrm{D}}=0.25$

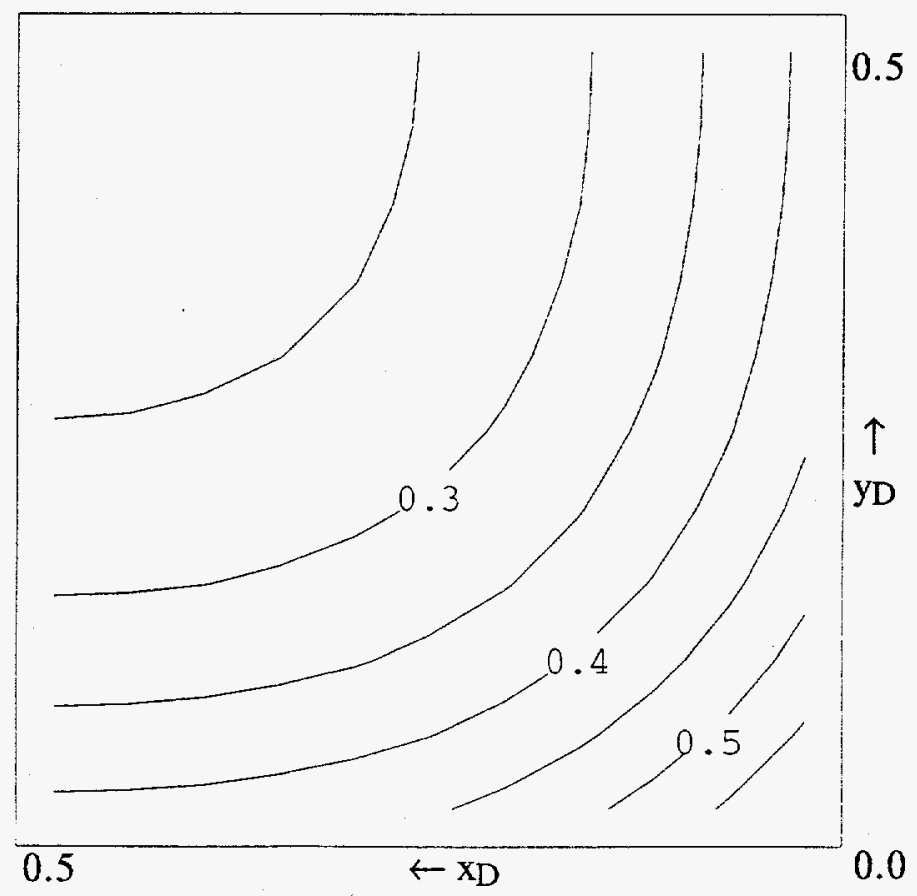

(c) $z_{D}=0.0$, surface layer

Figure 11. - 3-D dimensionless pressure drawdown for constant flow rate $\left(t_{D}=0.032\right)$ 


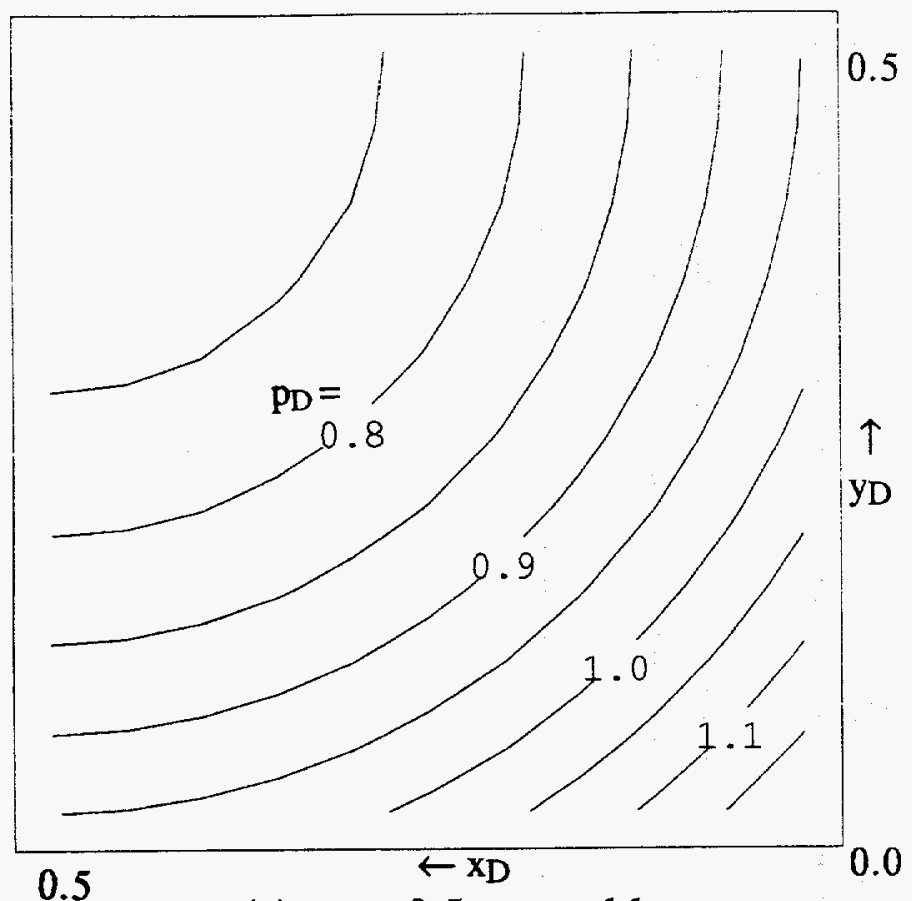

(a) $\mathrm{z}_{\mathrm{D}}=0.5$, central layer

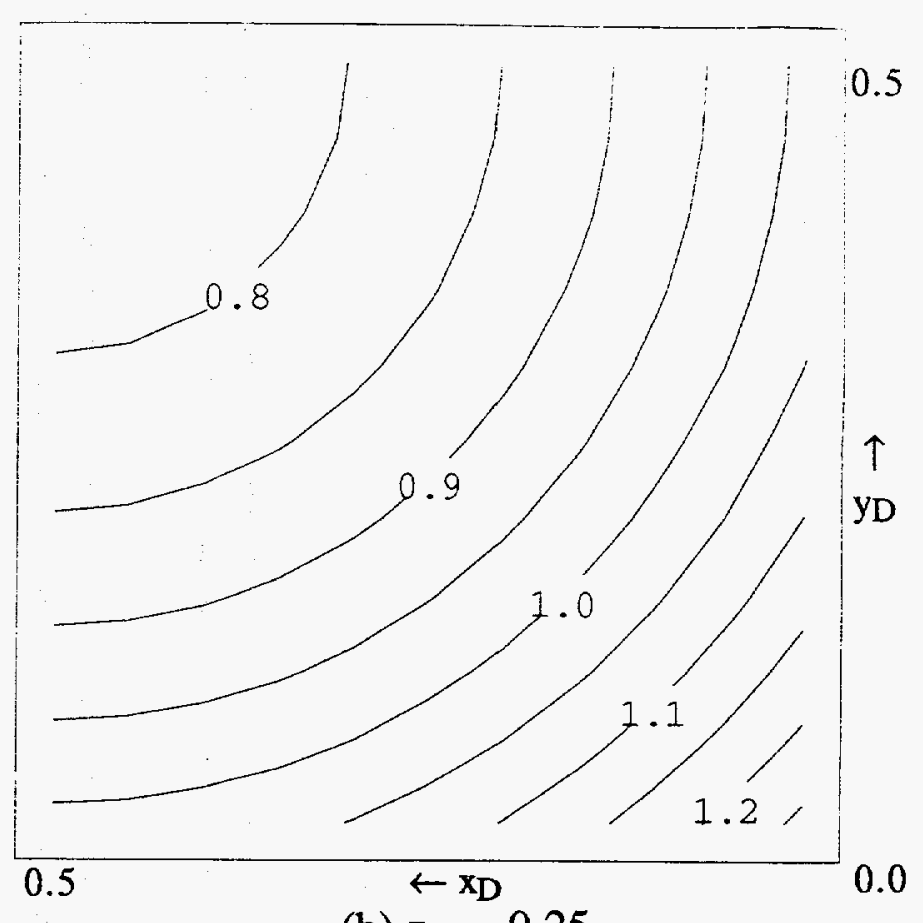

(b) $\mathrm{z}_{\mathrm{D}}=0.25$

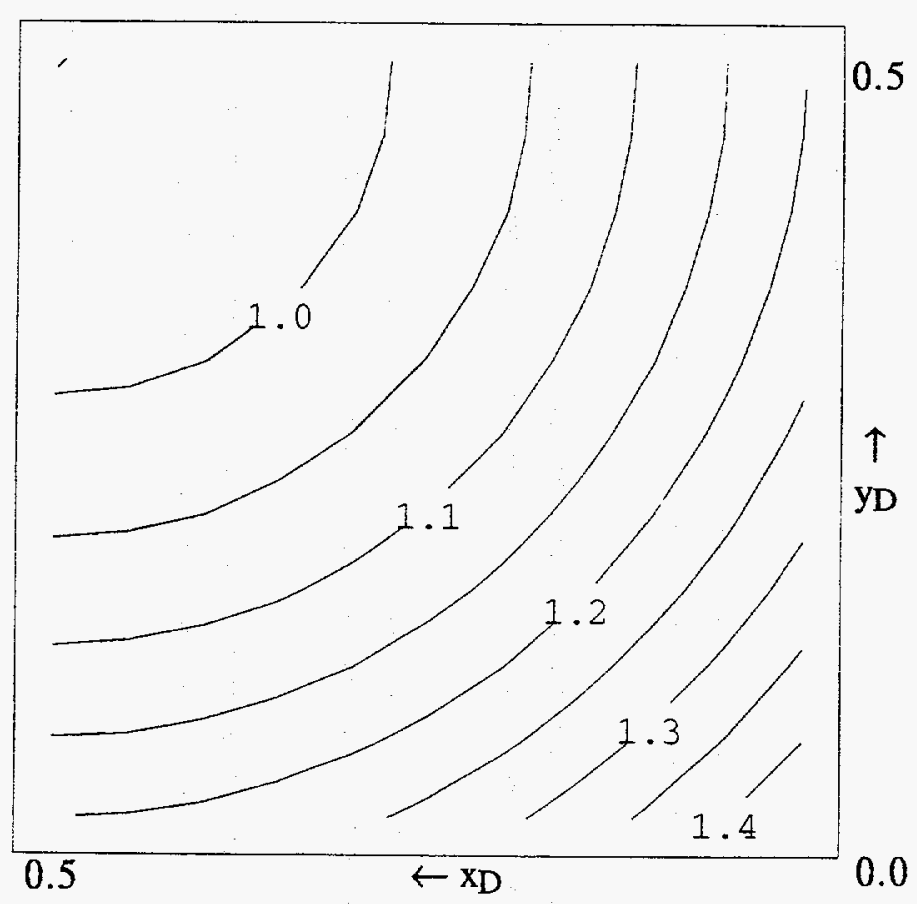

(c) $\mathrm{z}_{\mathrm{D}}=0.0$, surface layer

Figure 12. - 3-D dimensionless pressure drawdown for constant flow rate $\left(t_{D}=0.158\right)$ 


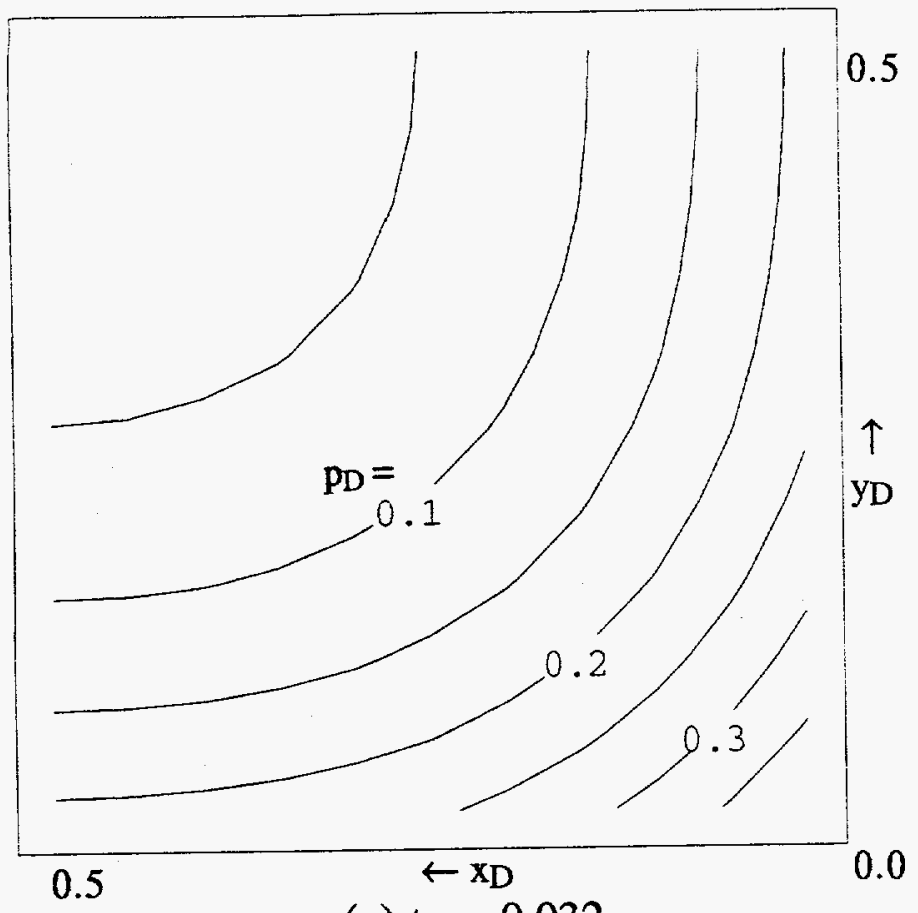

(a) $t_{D}=0.032$

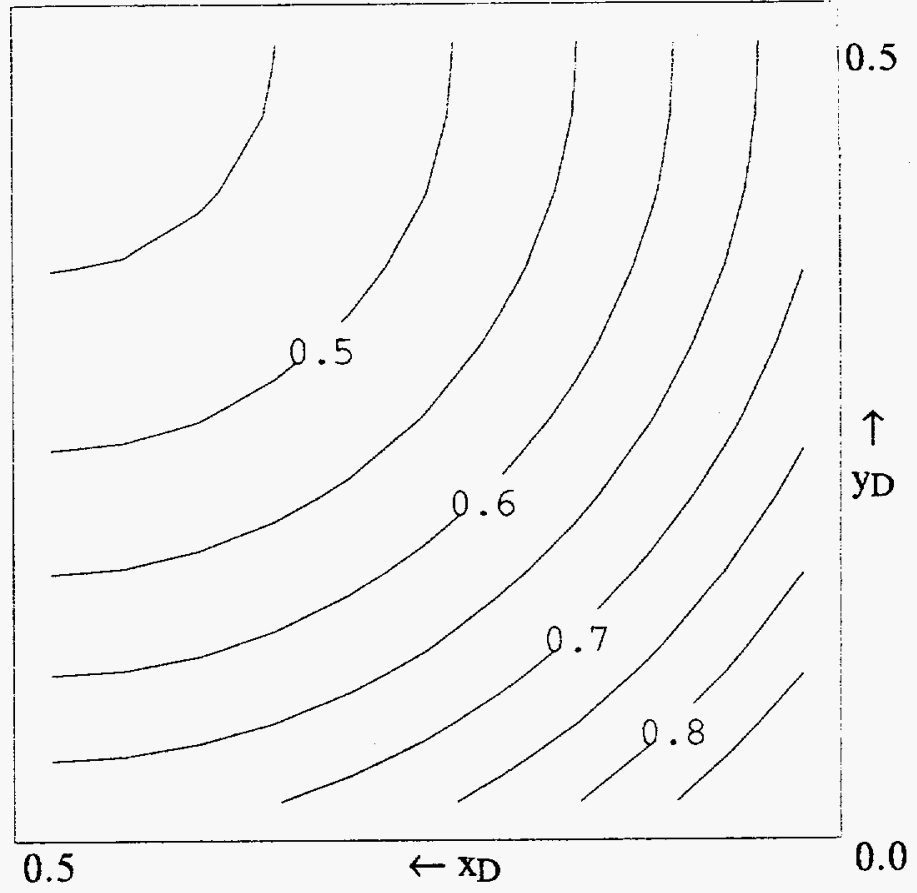

(b) $t_{D}=0.158$

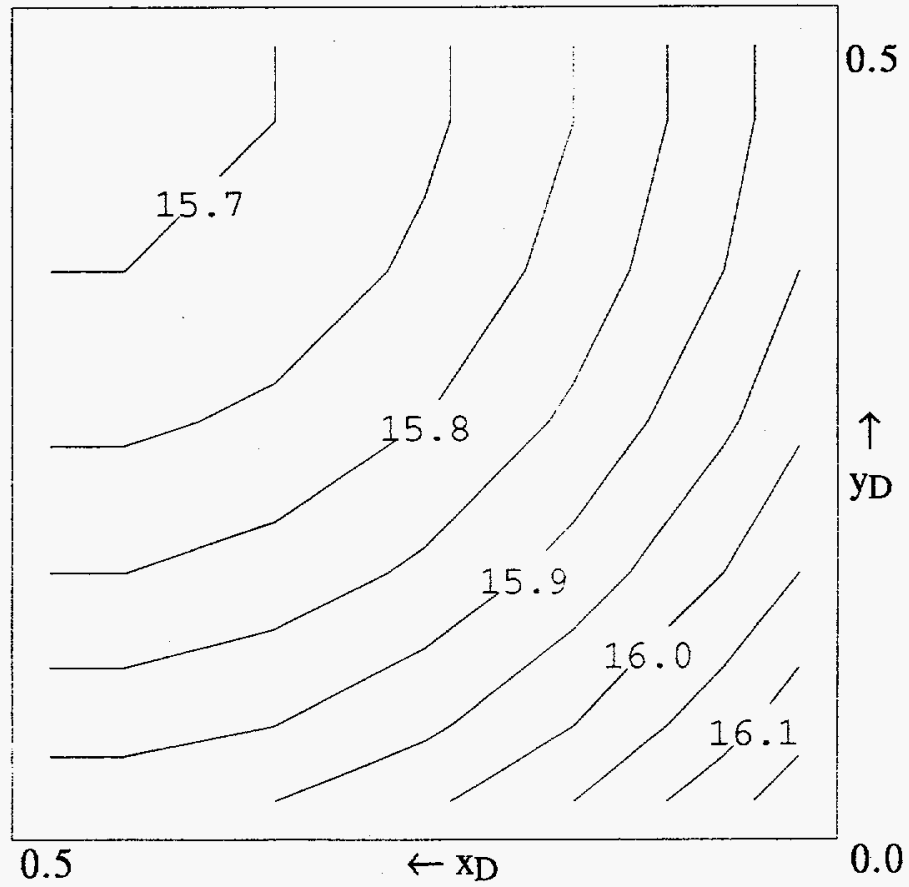

(c) $t_{D}=4$

Figure 13. - 2-D dimensionless pressure drawdown for constant flow rate 


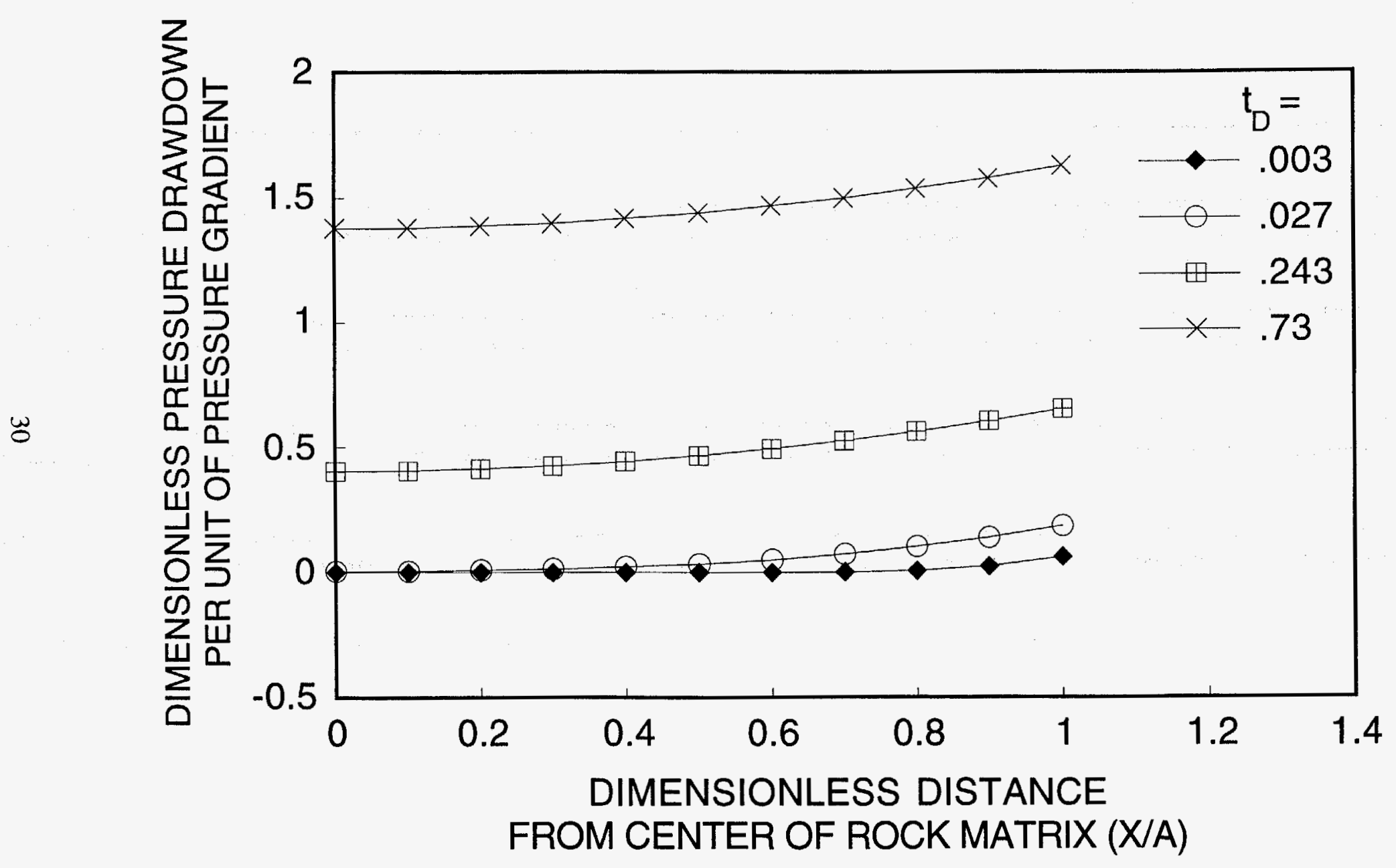

Figure 14. - 1-D dimensionless pressure drawdown for constant flow rate 


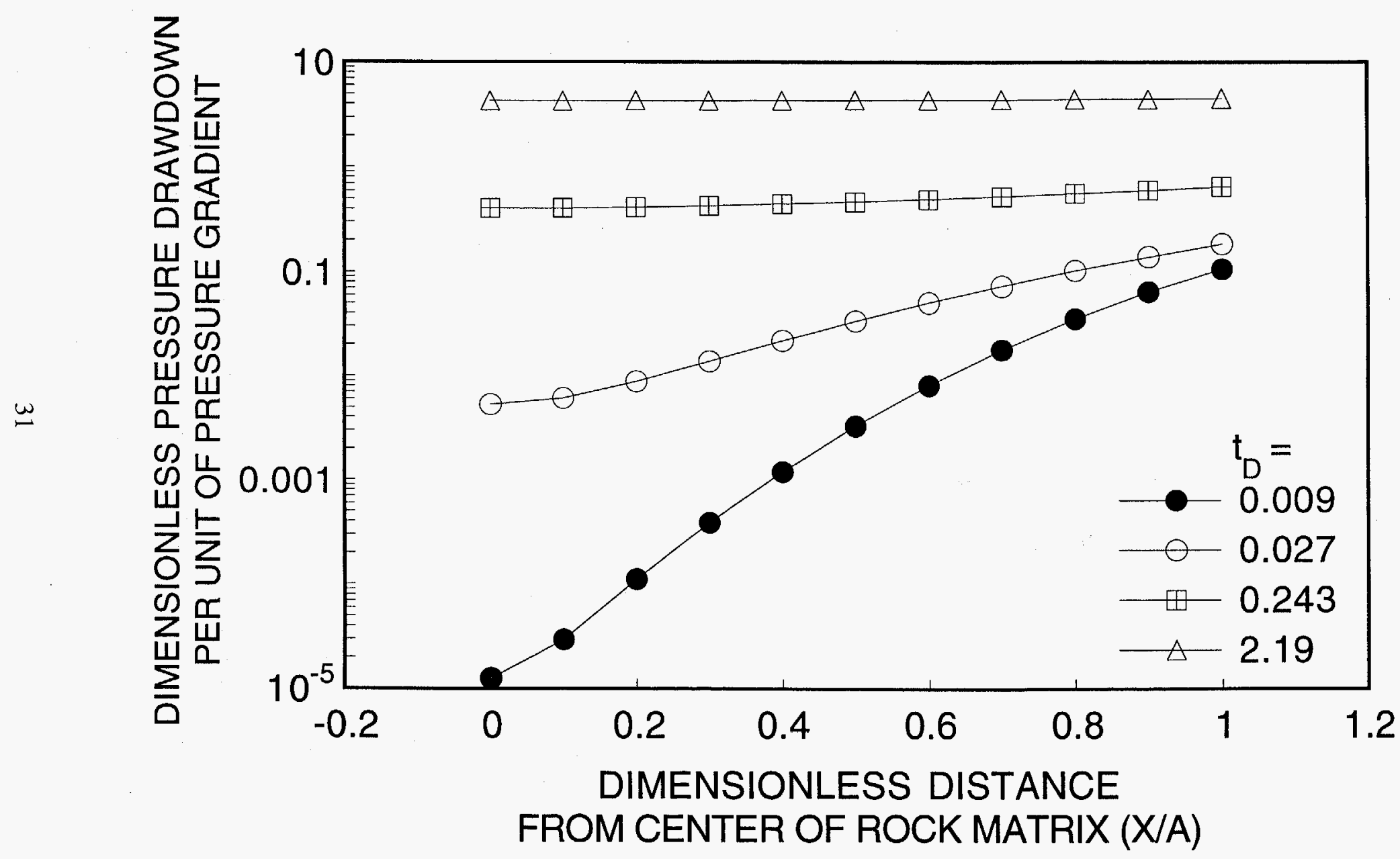

Figure 15. - 1-D dimensionless pressure drawdown (semilog plot) for constant flow rate 


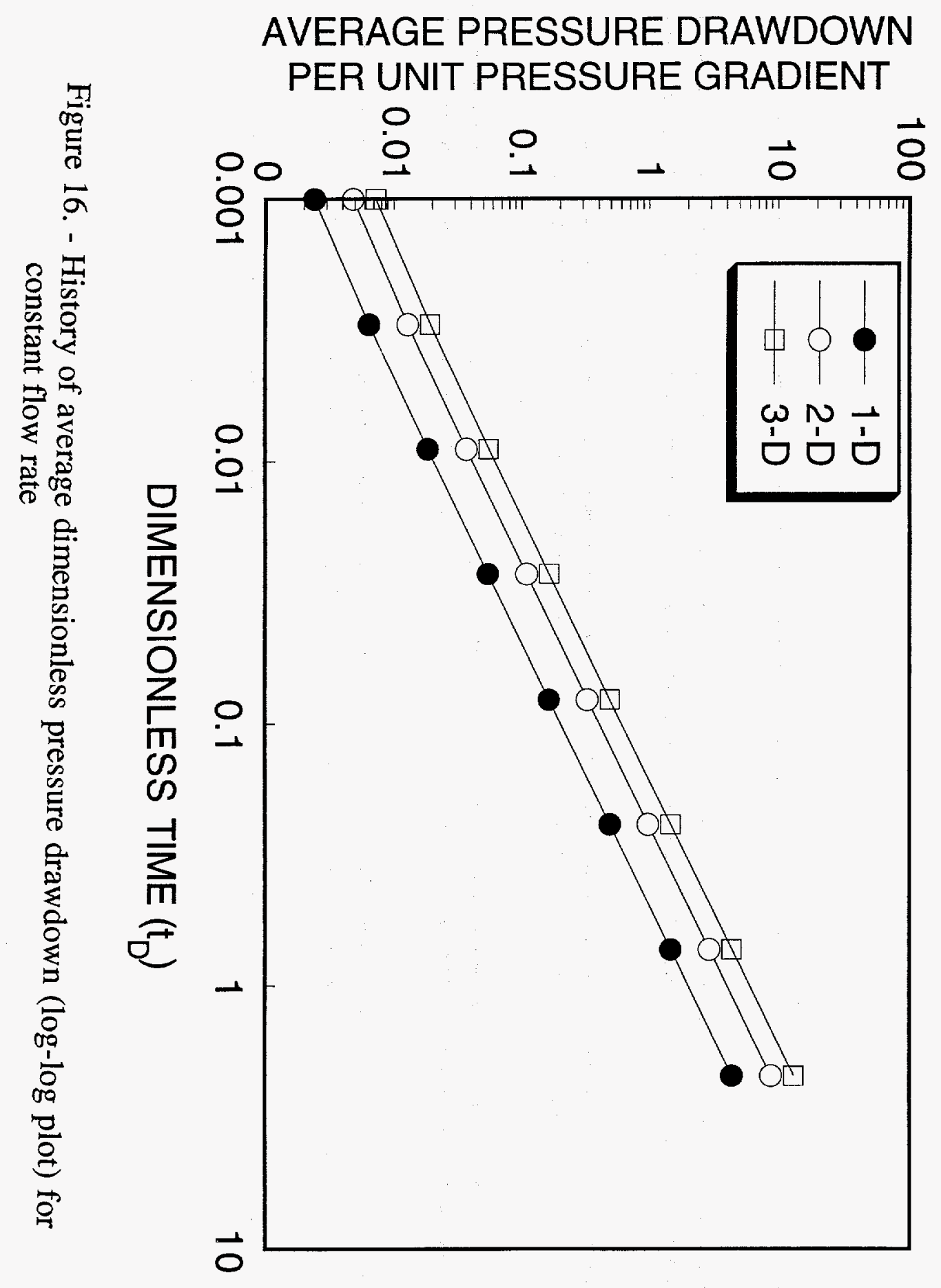




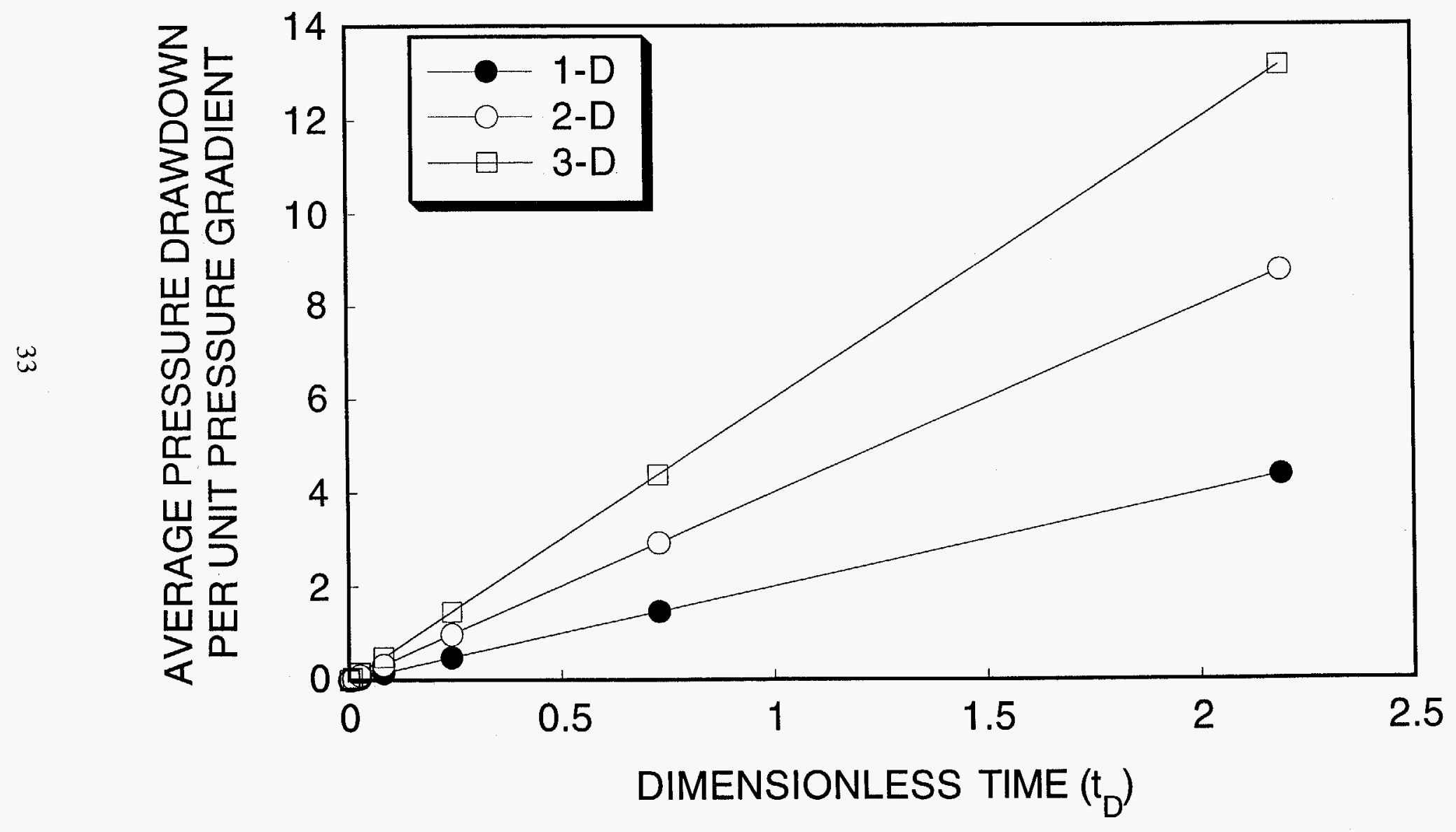

Figure 17. - History of average dimensionless pressure drawdown for constant flow rate 


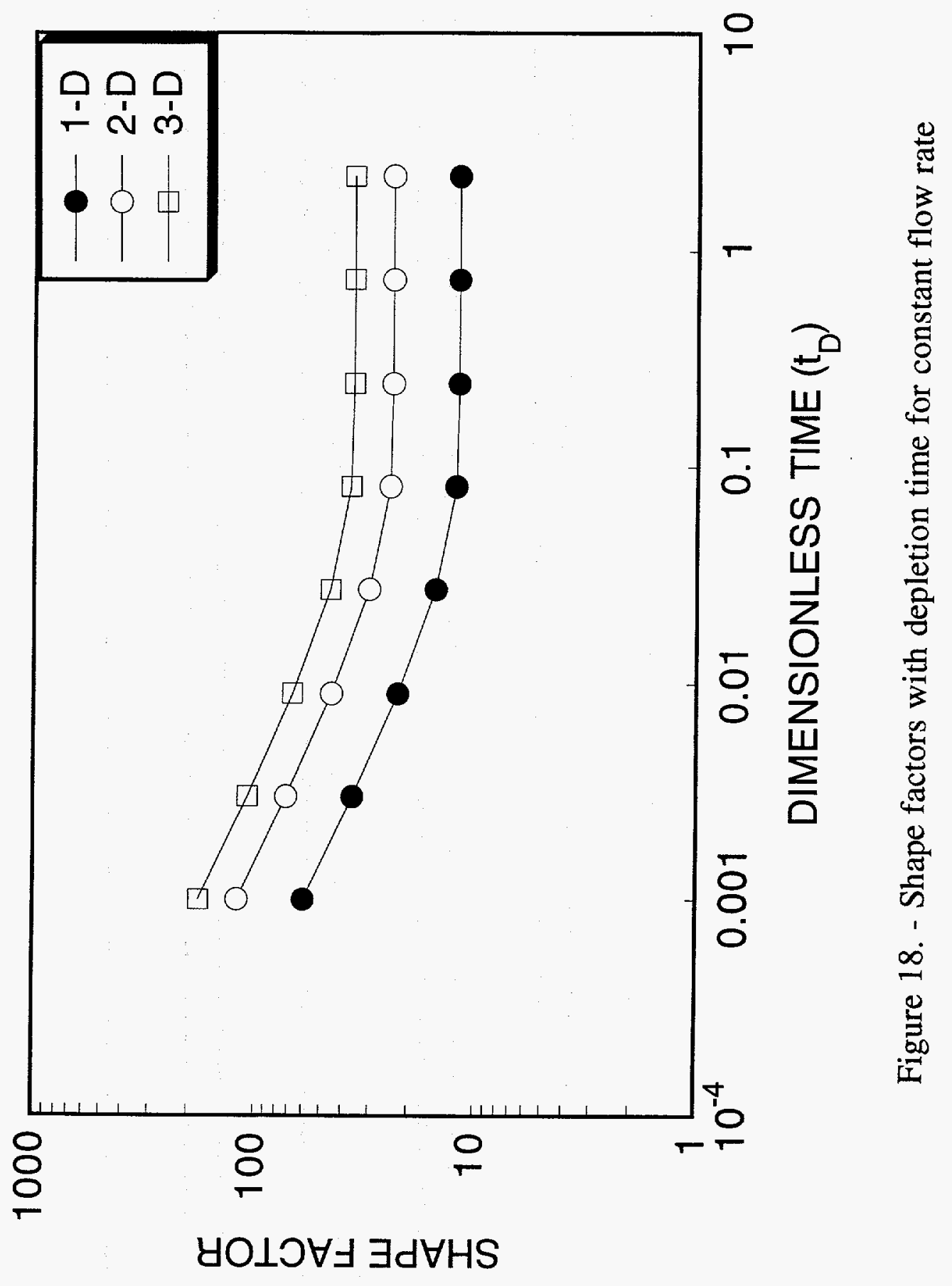




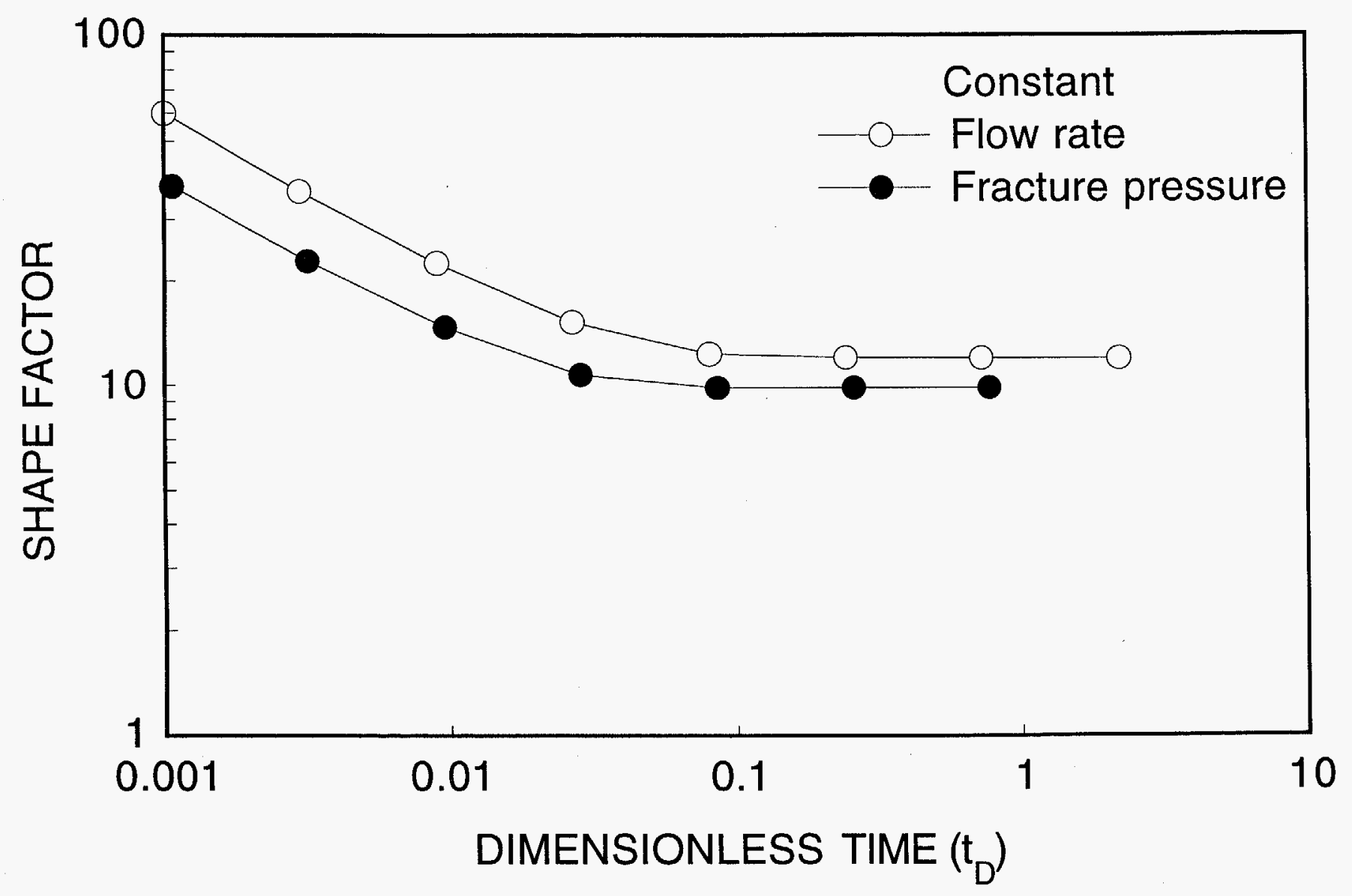

Figure 19. - Comparison of shape factors for constant fracture pressure and for constant flow rate 


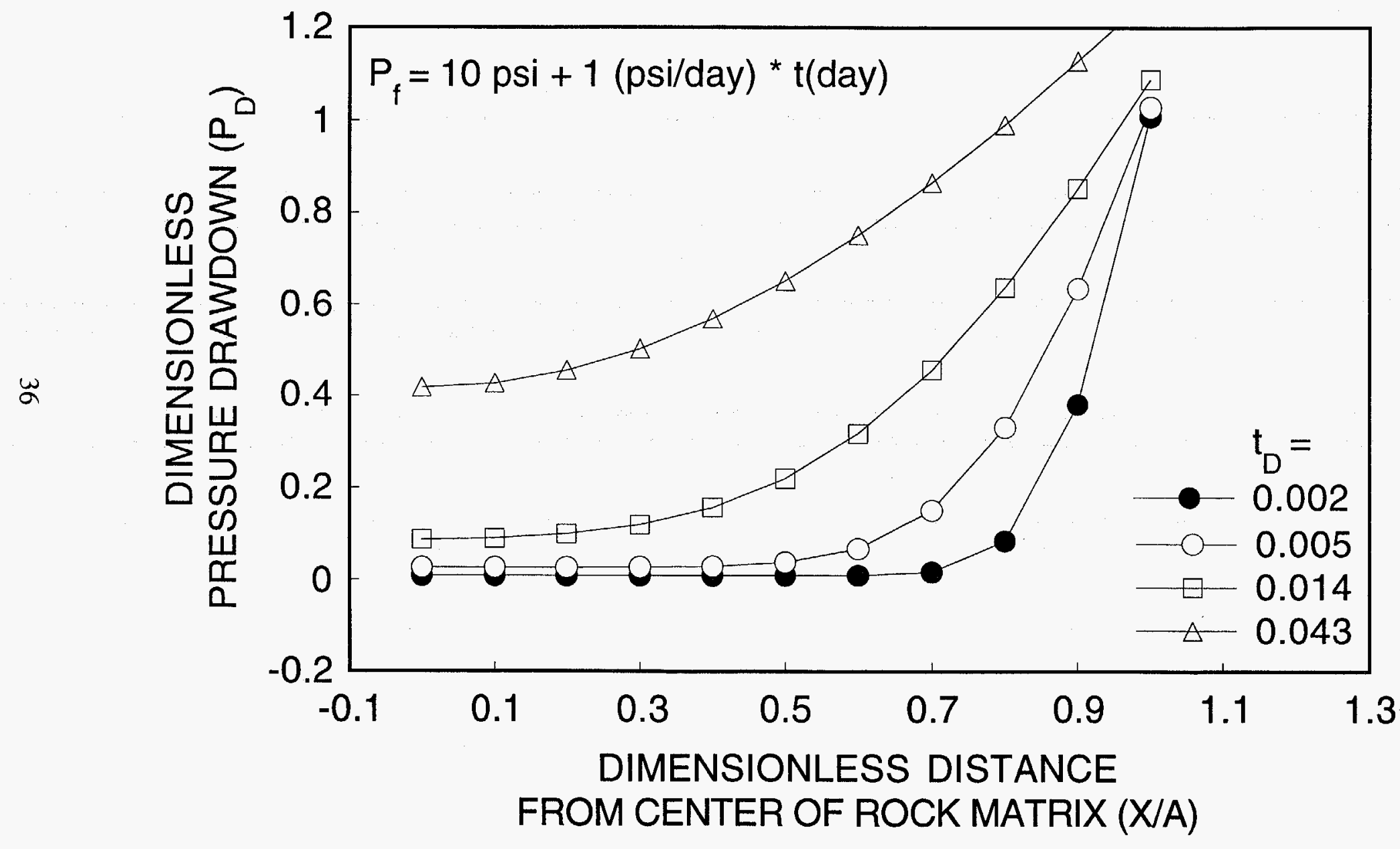

Figure 20. - 1-D dimensionless pressure drawdown for constant fracture pressure followed by constant flow rate 


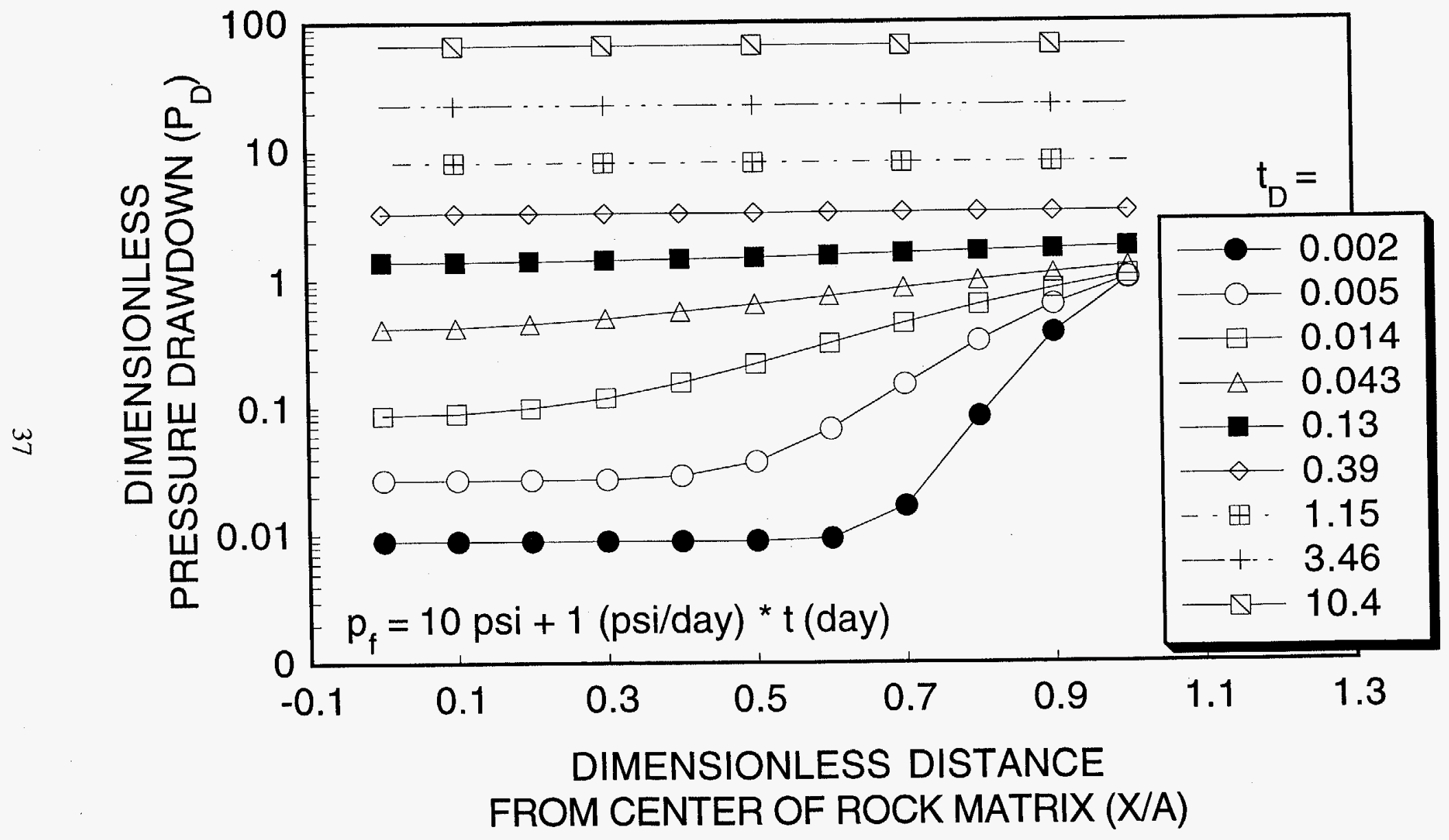

Figure 21. - 1-D dimensionless pressure drawdown (semilog plot) for constant fracture pressure followed by linearly declining fracture pressure 


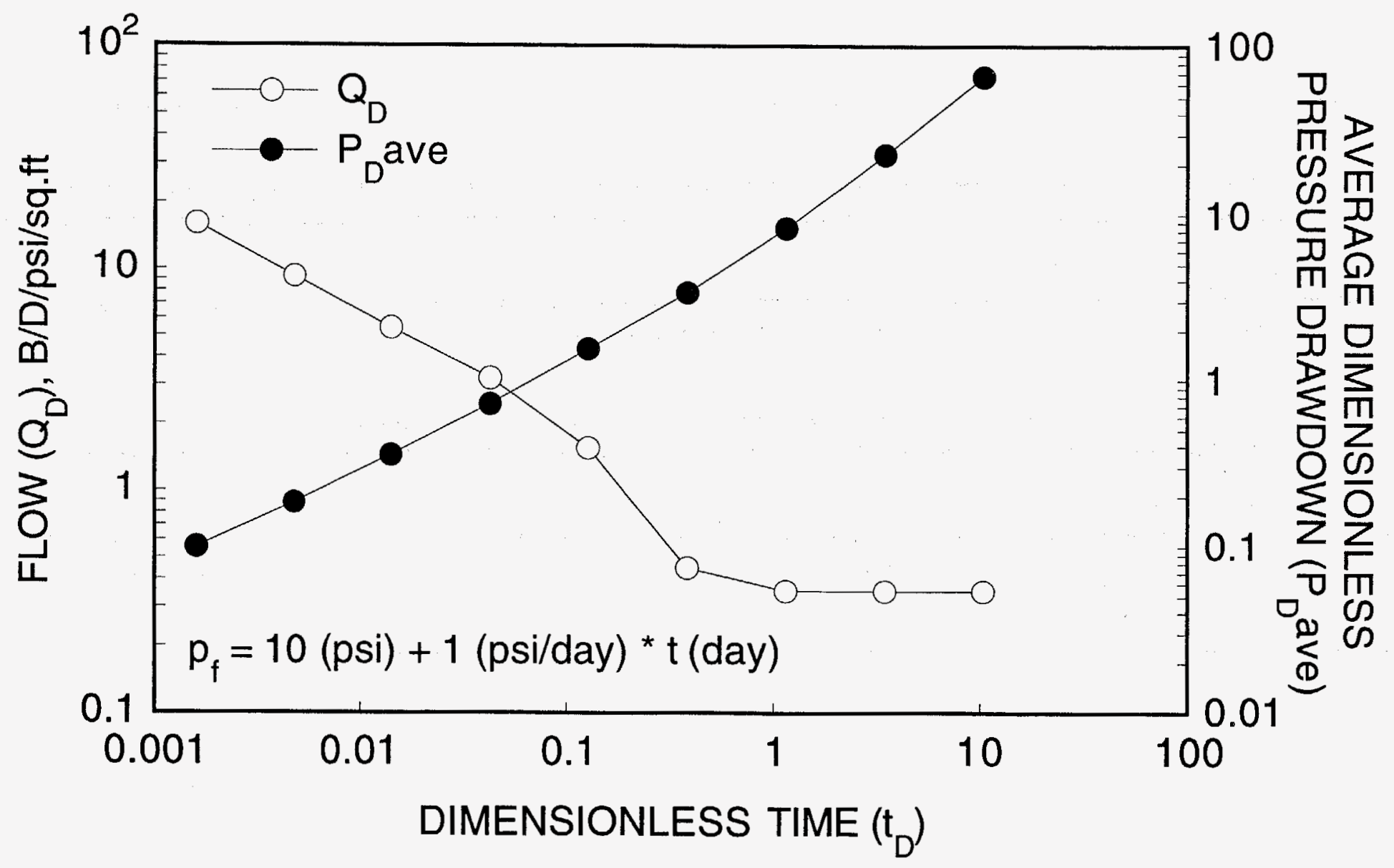

Figure 22. - 1-D flow rate and dimensionless pressure drawdown for constant fracture pressure followed by linearly declining fracture pressure 


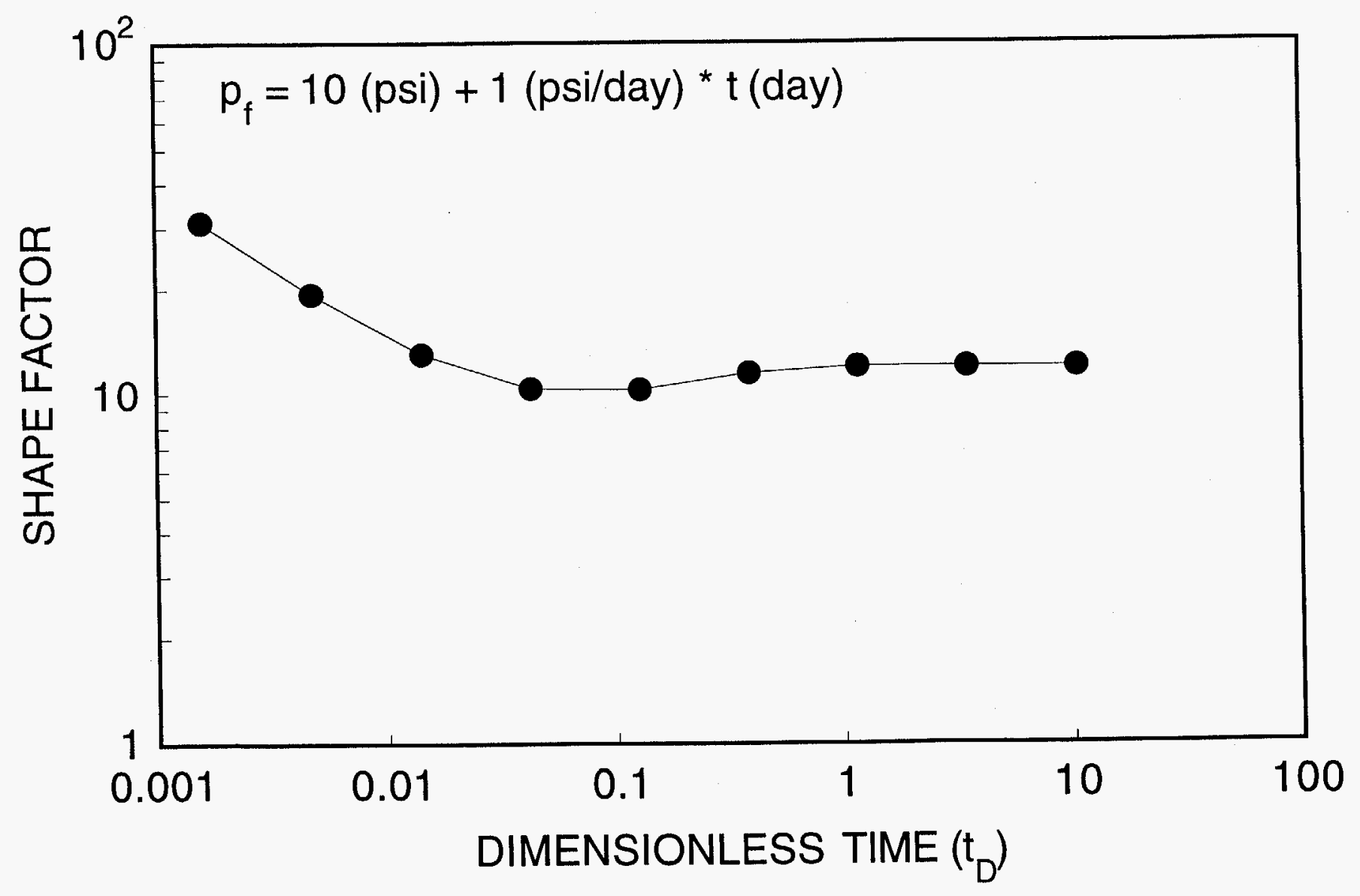

Figure 23. - 1-D shape factor for constant fracture pressure followed by linearly declining fracture pressure 


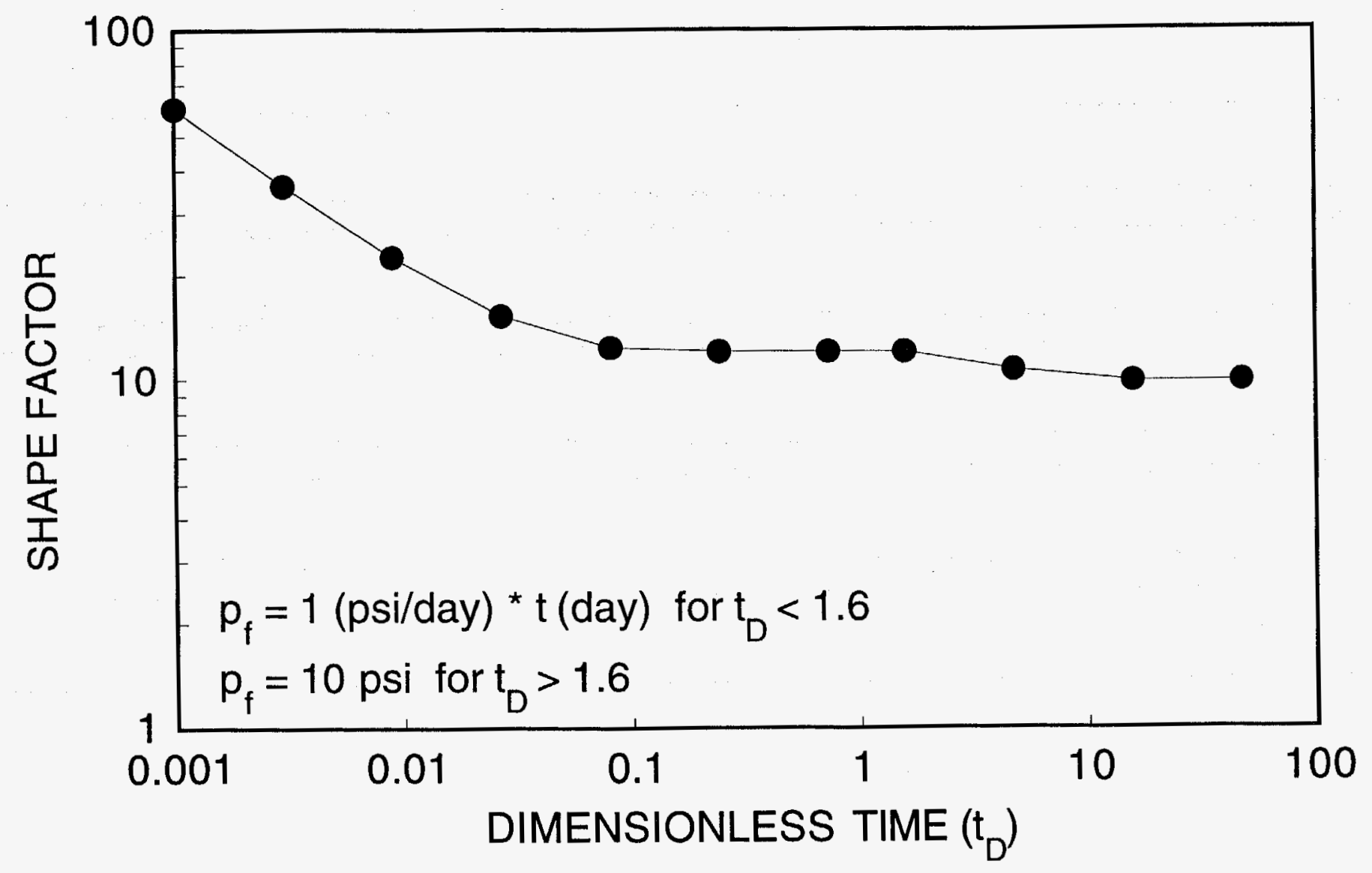

Figure 24. - 1-D shape factor for linearly declining fracture pressure followed by constant fracture pressure 